\title{
Developing bioimaging and quantitative methods to study 3D genome
}

\author{
Juntao Gao ${ }^{1, \dagger, *}$, Xusan Yang ${ }^{2, \dagger}$, Mohamed Nadhir Djekidel ${ }^{1}$, Yang Wang ${ }^{1}$, Peng $\mathrm{Xi}^{2}$ and Michael Q. Zhang ${ }^{1,3, *}$ \\ ${ }^{1}$ MOE Key Laboratory of Bioinformatics; Bioinformatics Division and Center for Synthetic \& Systems Biology, TNLIST; \\ Department of Automation, Tsinghua University, Beijing 100084, China \\ 2 Department of Biomedical Engineering, College of Engineering, Peking University, Beijing 100871, China \\ 3 Department of Biological Sciences, Center for Systems Biology, the University of Texas at Dallas, Richardson, TX 75080-3021, \\ USA \\ *Correspondence: jtgao@biomed.tsinghua.edu.cn, michaelzhang@tsinghua.edu.cn
}

Received November 11, 2015; Revised January 13, 2016; Accepted January 24, 2016

\begin{abstract}
The recent advances in chromosome configuration capture (3C)-based series molecular methods and optical superresolution (SR) techniques offer powerful tools to investigate three dimensional (3D) genomic structure in prokaryotic and eukaryotic cell nucleus. In this review, we focus on the progress during the last decade in this exciting field. Here we at first introduce briefly genome organization at chromosome, domain and sub-domain level, respectively; then we provide a short introduction to various super-resolution microscopy techniques which can be employed to detect genome 3D structure. We also reviewed the progress of quantitative and visualization tools to evaluate and visualize chromatin interactions in 3D genome derived from Hi-C data. We end up with the discussion that imaging methods and 3C-based molecular methods are not mutually exclusive - actually they are complemental to each other and can be combined together to study 3D genome organization.
\end{abstract}

Keywords: 3D Genome; quantitative methods; bioimaging; super resolution

\section{INTRODUCTION}

In eukaryotic nucleus, the organization of chromatin is very complex. Highly condensed chromatin and huge numbers of components, such as transcription factors, chromatin proteins and RNA-processing factors, cram together in a very small volume. Essential nuclear processes such as transcription, replication, and repair occur at spatially defined locations in the nucleus. Accumulating evidence suggests that the expression of many genes is correlated with their positions in cell nucleus, and the spatial organization of chromatins has played essential role in regulating transcriptional activity [1]. How these could be done is one of the greatest challenges in molecular biology.

DNA helix is hierarchically packaged into chromatin in an elegant way, and eventually form a chromosome in the eukaryotic nucleus over several levels of higher-order structures [1], indicating that a range of microscopy techniques with spatial and temporal scales that cover several orders of magnitude are necessary to understand the organization principles at different levels in a chromosome. For example, the structure of nucleosomes, the fundamental organization unit of chromatin, has been elucidated by X-ray crystals at nanometer scale [2]. The structure of "beads-on-a-string" fiber, which has a diameter of $11-\mathrm{nm}$ and is the very first level of chromatin organization, is also well-understood through Electron Microscope [33]. However, substructure at the scale of $10-200 \mathrm{~nm}$ is poorly understood, especially in live cells, partly due to the requirement of biological system that the dynamics, process and function in biology need to be measured with high spatial (approximately nanometer) and temporal (approximately microsecond to millisecond)

\footnotetext{
${ }^{\top}$ These authors contributed equally to this work.

This article is dedicated to the Special Collection of Recent Advances in

Next-Generation Bioinformatics (Ed. Xuegong Zhang).
} 
resolution, partly due to the physical limitations of electron microscopy with no temporal resolution at all and standard optical microscopy with spatial resolution at $200 \mathrm{~nm}$ because of light diffraction, and partly due to the mutually exclusive nature of temporal and spatial resolution, as high spatial resolution is normally achieved only at long measurement time and thus lowers temporal resolution, in order to obtain high signal-to-noise ratio (SNR). For example, there is still debate about the existence of the $30 \mathrm{~nm}$ chromatin fiber in vivo $[3,4]$. Despite considerable efforts from researchers during the past three decades, there are still a lot of discussion and debate on the higher-order levels of chromatin structure, such that the structure of $30-\mathrm{nm}$ chromatin fiber is supposed to be the second structural level of chromatin organization [3].

Fortunately, over the last decades, various superresolution (SR) techniques with subdiffraction spatial resolution of 10-100 $\mathrm{nm}$ have been developed (for recent reviews of super-resolution techniques, see $[5,6])$, in order to fulfill the special requirements in biological system. Super-resolution is achieved through On-Off modulation mechanism, either in a targeted fashion such as Saturation-structured illumination microscopy (SSIM), stimulated emission depletion (STED) or in a stochastic fashion such as photoactivated localization microscopy
((f)PALM) or stochastic optical reconstruction microscopy (STORM). Super-resolution allows biological investigators to evaluate the location of specific genes or proteins at a precision that was never reached before (For example, the SR imaging of telomere loop [7]).

On the other hand, high-throughput molecular mapping assays derived from chromosome conformation capture (3C) [8] have been developed in parallel during the last decade. 3C-based molecular methods employ crosslinking and intramolecular DNA ligation to investigate the spatial interactions and relationship of different loci and even whole genomes. Among these approaches, Hi-C interrogates all possible cross-linked contacts at acceptable resolution within the whole genome [9-12].

\section{INTRODUCTION TO MODELS OF 3D GENOME ORGANIZATION}

Combining the established fluorescence microscopybased methods with molecular 3C-based approaches is giving us unprecedented power to investigate $3 \mathrm{D}$ genomic structure in prokaryotic and eukaryotic cell nucleus. We focus on the development of bioimaging and quantitative methods to study 3D genome in this review (Figure 1). At first we introduce 3D genome organization and various model of 3D genomes here. Next we provide a short

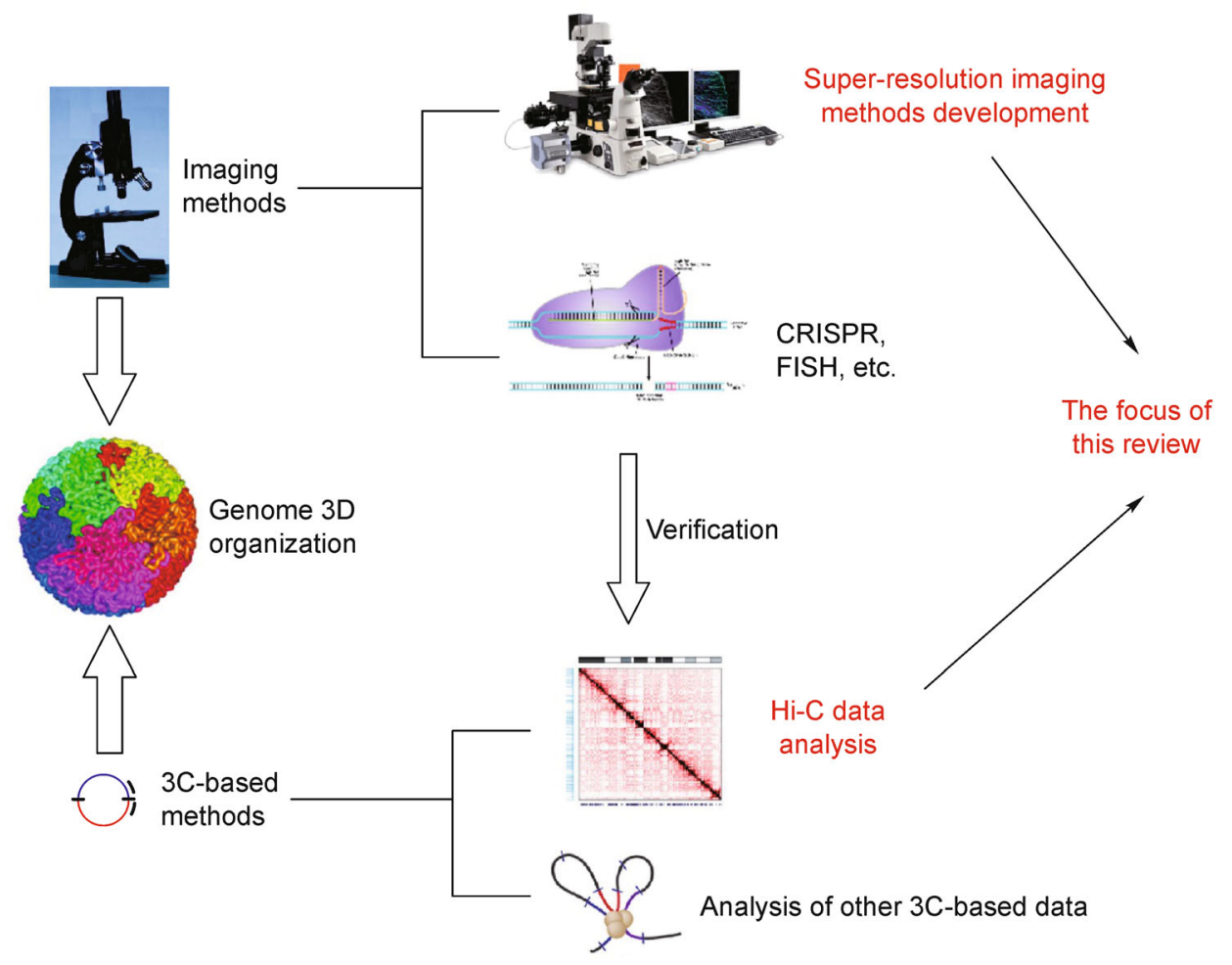

Figure 1. Genome 3D organization can be studied using imaging methods and 3C-based methods. The focus of this review is to use super-resolution microscopy methods and $\mathrm{Hi}-\mathrm{C}$ data analysis jointly to study genome organization. 
introduction to various super-resolution microscope (SRM) setting-ups and methods. Super-resolution imaging of tissue and organs has been extensively reviewed elsewhere, so these are outside the purview of this review. Then we review the development of quantitative and visualization software to evaluate and visualize the chromatin interactions, especially derived from $\mathrm{Hi}-\mathrm{C}$ data, in 3D genome. We end up with the discussion about how to confirm the information obtained from these methods, and a short outlook on the potential future development of these techniques.

\section{At chromosome level}

Nucleus is spatially compartmentalized into chromosome territories (CTs) [13]. In Eukaryotic cells, chromosomes and sub-nuclear organelles have their characteristic 3D positions or preferred positions relative to nuclear interior or periphery. At chromosome level, there are mainly three models to describe chromosome positioning during interphase, and another three for mitosis.

\section{Models for interphase chromosome positioning}

Rabl configuration: During interphase, chromosomes are specifically organized in eukaryotic cells. For example, in Schizosaccharomyces pombe, chromosomes are arranged in polarized manner, where telomeres of all chromosomes are also associated with each other on one side of nucleus, and centromeres are clustered close to spindle pole body (SPB) at the opposing hemisphere near nuclear periphery $[14,15]$ - This is called Rabl configuration, which is established during anaphase and thereafter maintained during interphase, but is disrupted during late interphase and early prophase. It is first described in nuclei of salamander larvae by Karl Rabl [16]. Rabl-like configuration also exists in other eukaryotic cells, such as Sacharomyces cerevisae [17], in the embryonic cells of Ascaris [18], in Drosophila melanogaster [19], in spermatocytes of the mosquito Aedes aegypti [20], fibroblasts of the treeshrew (Tupaia belangeri), the lymphocytes of the Indian muntjac, Chinese hamster fibroblasts [21], and some plants [22]. However, it was reported that chromosome alignment in Rabl configuration might not be important to control gene expression [23].

Radial positioning: Accumulating evidence from fluorescence in situ hybridization (FISH) and $\mathrm{Hi}-\mathrm{C}$ suggests that, in many cell types, the spatial organization of chromosomes is related to gene density, with genedense chromosomal regions or whole chromosomes closer to the center of the nucleus, gene-poor chromosome more frequently at the periphery, and with the clustering of the rDNA-containing chromosomes close to nucleoli [10,24-26]. This model of radial positioning not only is specific to human chromosome 18 and 19 [13,27] and all other human chromosomes [25], but also has been observed in other species such as rodents, birds, primates, suggesting that radial positioning is probably a general feature of the organization in eukaryotic cells [28]. Furthermore, radial positioning suggests that there might be a quantitative relationship between CT's gene density and CT's distance to nuclear center, according to the "spherical $1 \mathrm{Mb}$ chromatin domain" model [29]. However, gene-poor chromosomes can move away from nuclear periphery in quiescent or senescent human fibroblasts [30,31].

Preferential positioning: In this model, chromosomes occupy some preferential positions within cell nucleus. Evidence for this model comes from the so-called "mitotic rosettes" (or mitotic ring) [32], where chromosomes were arranged in a ring in the metaphase plate during metaphase, and homologues often occupy opposed positions diametrically in the ring. Similar evidence was extended into interphase cells as well [33]. However, no evidence indicates that a given chromosome must have a specific neighbor in the nucleus [34], and it is shown that in at least chicken cells, there is no preferential pattern for the relative positioning of chromosome territories [35].

Models for mitotic chromosome positioning

Model 1: Physical linkage between chromosomes. Chromosome positioning in metaphase rosettes of human cells is not random [32]. During metaphase, chromosomes are attached to each other physically, and this linkage in interphase and mitosis contributes to the conservation of neighborhood chromosomal relations. Symmetrical chromosome positions in sister cells indicate that chromosome position reconstruction depends on the metaphase configuration [36]. During chromatin condensation, relative neighborhoods are maintained [37]. During chromatin decondensation, there are no major relative positional changes [38]. On the other hand, one study did not confirm the configuration of non-random rosette during metaphase [39].

Model 2: Chromosome tethering by the nuclear envelope. During mitosis, chromosome tethering with broken down nuclear envelope makes the chromosome positioning random. In early G1, some chromosomes set up specific interactions with nuclear envelope (gene-poor chromosomes tether to peripheral positions) and establish radial positioning. There are chromosome repositioning dynamics during early G1 phase of live cells [40,41]. After mitotic division, typical peripheral localization of gene-poor chromosomes was observed in cells [30]. This model could explain how radial order could be established during mitosis, though it cannot explain why 
chromosome arrangements can be resembled in clonally descendent cells.

Model 3: Chromosome-specific timing of segregation. When chromosomes congress to the flat metaphase plate along spindle axis, the spatial order information of chromosomes is lost. However, the chromosome order of non-random relative positions is re-established during segregation in early anaphase by chromosome-specific anaphase onset, such that the order in daughter nuclei is similar to that in mother nucleus again. The increasing amounts of peri-centromeric heterochromatin could delay the timing of chromosome segregation. Chromosomal positions are maintained along the metaphase plate in daughter nuclei by linear segregation. Consistent with both radial positioning model and preferred neighborhoods model, chromosome-specific timing of segregation model does not exclude the possibility of chromosomespecific interactions with nuclear envelope, which might further modify post mitotic chromosome positioning during early G1 [34]. One thing we have to point out is that, none of the models mentioned above is mutually exclusive.

\section{At the sub-chromosome level}

Compartment A and B: Individual chromosomes can be further folded into $\sim 5 \mathrm{Mb}$ size compartment $\mathrm{A}$ and $\mathrm{B}$ which correspond to open and closed chromatin, respectively [11]. Open compartment A is normally enriched in transcription activity, DNase I hypersensitivity, high GC content, and histone modifications associated with H3K36me3 (active chromatin mark) and H3K27me3 (poised chromatin mark) [28]. In contrast, compartment B often has higher interaction frequencies, higher level of silencing $\mathrm{H} 3 \mathrm{~K} 9 \mathrm{me} 3$ mark and stronger tendency toward self-association. The position of compartment B can be highly correlated with lamin associated domains and late replication timing. The distribution of compartment $\mathrm{A}$ and $\mathrm{B}$ is highly stable along chromosomes across all mammalian cell types examined so far.

Domains and boundaries: Genomes can be further partitioned into distinct globular units called "topological associated domains"(TADs). Dixon et al. first identified these megabase-sized local chromatin interaction TADs (between 0.5 and $1 \mathrm{Mb}$ ), which are highly conserved between species and preserved in different cell types. TADs might be adjacent along chromosomes, but can remain spatially distant. Loci within TADs interact with each other much more frequently than those outside of the domain [9]. Genes within TADs tend to be coexpressed, therefore, most long-range gene regulation by enhancers is constrained inside of TADs [28].

On the other hand, the boundaries of TADs delineate the original TADs by constraining the spread of heterochromatin. TAD boundaries are enriched in binding sites for the architectural proteins CTCF and cohesion, transcription start sites (TSSs), corresponding histone marks (such as H3K4Me3, H3K9Me1, H3K9Me2), many housekeeping genes, some tRNA genes, and/or short interspersed nuclear elements. Enrichment of cohesion and CTCF at the boundaries may imply a role of these proteins in establishing and defining a TAD, which is not yet completely understood.

All of these features suggested that TADs might be universal building blocks or inherent units in mammalian genomes, though TADs have not been identified in yeast, bacteria, or larger plant genomes yet [42-44].

Sub-TADs: Larger conserved TADs are composed of smaller domains $(\sim 0.2 \mathrm{Mb})$ [45], which can be called "sub-TADs", because of their sub-megabase size [46]. Sub-TADs are more tissue specific and the function of boundaries at subdomains is uncertain.

\section{METHODS FOR IMAGING AT SINGLE MOLECULE LEVEL}

Seeing is believing. It is important to utilize microscopy to observe the co-localization or close physical proximity of given genes or chromatins, in order to further illustrate how genes are regulated in 3D fashion. The optical resolution in fluorescent microscopy determines the depth of biological study, as it describes how fine we can look into the cell. For centuries, the resolution of microscopy has been restricted to $\sim 200 \mathrm{~nm}$ and $\sim 600 \mathrm{~nm}$ for lateral and axial situations, respectively, due to the barrier of diffraction limit. Whereas inside the crowded cell, the subcellular organelles are typically of the size of several to tens of nanometers.

Various novel super-resolution microscopy techniques emerged during the last two decades. The milestones and breakthroughs made by super-resolution microscopy was recognized by the 2014 Nobel Prize in Chemistry. The general methods to achieve super-resolution can be largely categorized into either structured illumination, including STED and SIM; or stochastic photoswitching/ fluctuation and localization analysis (Figure 2), including PALM, STORM, super-resolution optical fluctuation imaging (SOFI) and Bayesian analysis of the Blinking and Bleaching (3B analysis) [51]. These breakthroughs offer biologists new tools for far-field fluorescence imaging of sub-cellular structures at resolution beyond diffraction limit. Therefore, SRM was employed in a quite broad range of biology research fields and topics such as cellular structures, membrane organization, dynamic assembly of proteins in cells. The rapid progress now allows 3D imaging with $10-100 \mathrm{~nm}$ axial resolution and video-rate SRLM in live cells. SRM has been applied in biology so widely that it is difficult to cover all of them in 
this review. Therefore, we only focus on bioimaging methods directly related, to try to answer one important biology question: how genome is organized in $3 \mathrm{D}$ fashion?

\section{Localization super-resolution microscopy (LSRM)}

Localization super-resolution microscopy is an imaging technique that uses time-resolved localization and sequential activation of photoswitchable fluorophores to create super-resolution images. This strategy is generally based on time-series data containing the information of several isolated fluorophores in each frame. To obtain a super-resolution image, at any given moment, only one subset of fluorophores, which is optically resolvable, is activated to determine the position of each fluorophore with high precision. The fluorophore is subsequently deactivated, and another subset is activated and imaged. This process needs to be repeated many times to localize numerous fluorophores, and a super-resolution image was finally reconstructed from these image data.

Localization SRM is based on two important concepts: photoswitchable/photoactivatable fluorescent molecule, and the algorithm to localize single fluorescent molecules. Fluorescence photoswitching or photoactivation can be any process which results in on/off transitions, such as blinking or transient binding. Therefore, based on this principle, besides PALM/STORM, a lot of other LSRM techniques have been developed in the recent years, including CSTORM [52], PAINT [53,54], QuickPALM [55], BaLM [56], SOFI [57], 3B [51,58] and QDB3 [59].

Both the modulation speed and the harvested photons determine the temporal resolution of these super-resolution techniques. Of them, PALM/STORM requires no more than one emitter in the diffraction spot in the ON state in each frame. In contrast, BaLM, SOFI, 3B and QDB3 utilize stochastic blinking of fluorophores and reconstruct the blinking behaviors in a time-series data with respective algorithms. Taking into account of all the fluctuation information for a more robust localization analysis, Bayesian localization microscopy liberated the requirement of one emitter per spot.

LSRM has been used frequently to study genome organization (Table 1). Recently, a novel super-resolution technique based on fluorescent polarization demodulation (SPoD) was developed [50], which records additional information in each frame by modulating the polarization angle of incident excitation light. Unlike STORM/PALM behavior which needs time series frames to record for one SR image (usually hundreds of or thousands of frames),

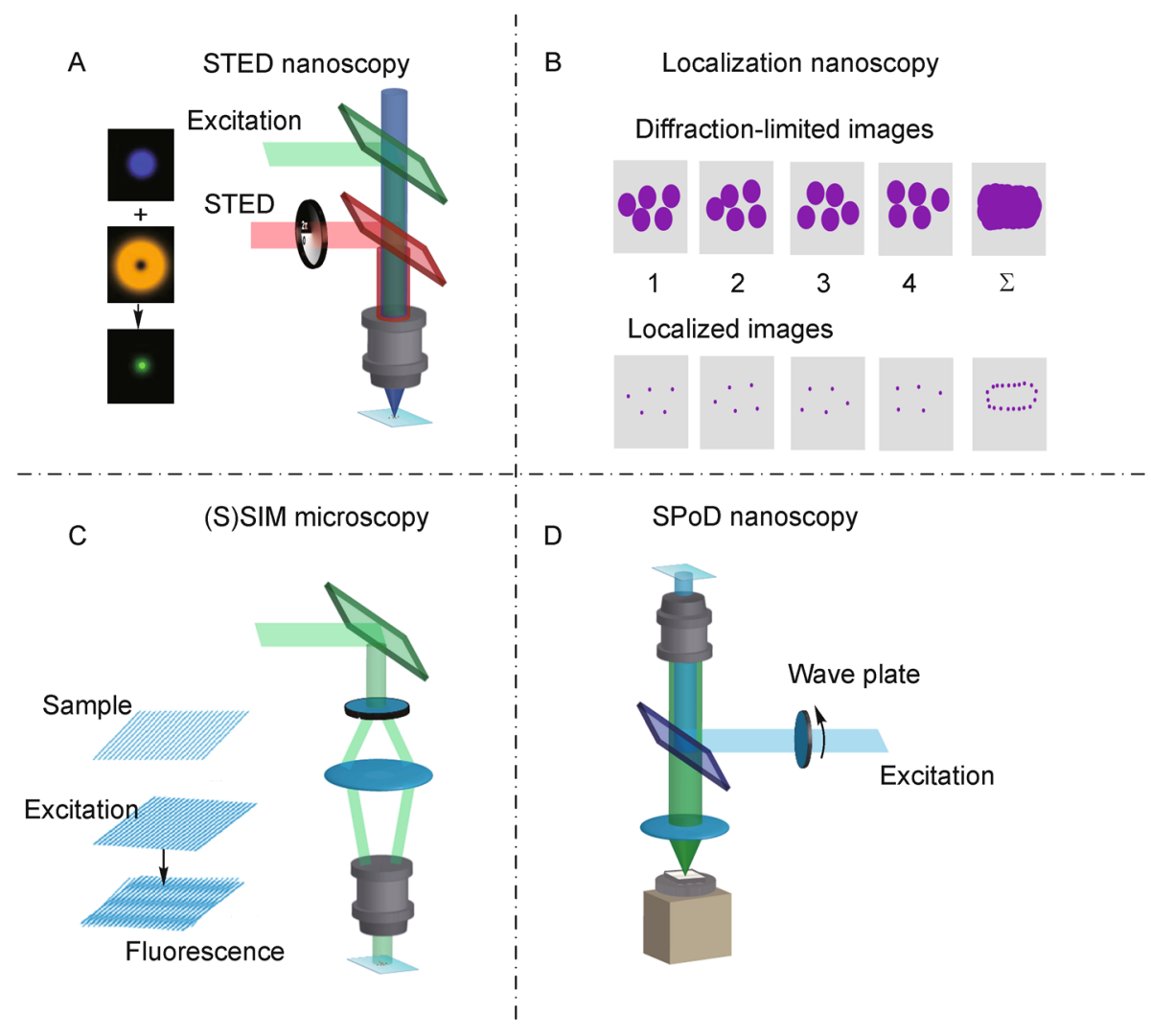

Figure 2. Super resolution methods for imaging genome at single molecules level. (A) STED microscopy [47,48], (B) Localization Microscopy, (C) (S)SIM [49], (D) SPoD Nanoscopy [50]. 
Table 1. PALM/STORM are used to investigate chromatin organization in live or fixed cells.

\begin{tabular}{|c|c|c|c|c|}
\hline \multirow{2}{*}{ Goal } & \multicolumn{2}{|c|}{ Method } & \multirow{2}{*}{ Conclusion } & \multirow{2}{*}{ Ref. } \\
\hline & SRM \& cell types used & Experimental conditions & & \\
\hline $\begin{array}{l}\text { To map protein localization in } \\
\text { the chicken kinetochore }\end{array}$ & $\begin{array}{l}\text { PALM + STORM, Dual color. } \\
\text { Chicken DT40 conditional } \\
\text { knockout cell lines }\end{array}$ & $\begin{array}{l}\text { CENP-A Alexa647 and } \\
\text { Dronpa-CENP-A (photo- } \\
\text { blinking was induced). Labeling } \\
\text { density should be high enough }\end{array}$ & $\begin{array}{l}\text { For the first time, SRM can } \\
\text { distinguish between canonical } \\
10 \text {-nm \& } 30 \text {-nm fibers in stretched } \\
\text { chromatin }\end{array}$ & {$[60]$} \\
\hline $\begin{array}{l}\text { How to image condensed mitotic } \\
\text { chromosomes? }\end{array}$ & $\begin{array}{l}\text { PALM to image EGFP-histones } \\
\text { in Drosophila embryo fixed by } \\
\text { fixation buffer }\end{array}$ & $\begin{array}{l}\text { EGFP-H2AvD (i.e., EGFP-his- } \\
\text { tones) }\end{array}$ & $\begin{array}{l}\text { Chromosome is composed of } \\
\text { 70 nm filament-like structures } \\
\text { formed from } 35-\mathrm{nm} \text { sub- } \\
\text { filaments, empty cavities \& } \\
\text { unstructured chromatin }\end{array}$ & {$[61]$} \\
\hline $\begin{array}{l}\text { How to infer density fluctuation } \\
\qquad \& \text { structural features? }\end{array}$ & $\begin{array}{l}\text { SPDM + statistical methods. } \\
\text { Human fibroblast and HeLa } \\
\text { cells }\end{array}$ & H2B-emGFP & $\begin{array}{l}\mathrm{H} 2 \mathrm{~B} \text { distribution remains the } \\
\text { same at scale }<100 \mathrm{~nm} \text { as a } \\
\text { function of cell type, but different } \\
\text { significantly as function of } \\
\text { expression method }\end{array}$ & {$[62]$} \\
\hline $\begin{array}{l}\text { What is the distribution of } \\
\text { nuclear protein } \mathrm{H} 2 \mathrm{~A} \& \\
\text { Snf } 2 \mathrm{H} \text { ? }\end{array}$ & $\begin{array}{l}\text { Dual color localization micro- } \\
\text { scopy. Human U2OS fixed } \\
\text { cells }\end{array}$ & $\begin{array}{l}\text { Histone H2A-mRFP1 and the } \\
\text { chromatin remodeling factor } \\
\text { Snf } 2 \text { H-GFP, in mammalian cell } \\
\text { nucleus }\end{array}$ & $\begin{array}{l}\text { The relative amounts of } \mathrm{H} 2 \mathrm{~A} \\
\text { and } \mathrm{Snf} 2 \mathrm{H} \text { differ throughout the } \\
\text { cell, suggesting chromatin } \\
\text { regions locally enriched with } \\
\text { Snf } 2 \mathrm{H} \text { do exist }\end{array}$ & {$[63]$} \\
\hline $\begin{array}{l}\text { Bacterial chromosome } \\
\text { segregation }\end{array}$ & $\begin{array}{l}\text { PALM + EM. Bacterium } \\
\text { Caulobacter crescentus }\end{array}$ & $\begin{array}{l}\text { EYFP-ParA (nucleoid- } \\
\text { associated ATPase) }\end{array}$ & $\begin{array}{l}\text { ParA is organized as linear } \\
\text { polymer in the center of cell } \\
\text { body, similarly to eukaryotic } \\
\text { cells' mitotic spindles }\end{array}$ & {$[64]$} \\
\hline $\begin{array}{c}\text { What's structure and function } \\
\text { of most NAPs in bacteria? }\end{array}$ & $\begin{array}{l}\text { Spatial point statistics }+ \text { SR } \\
\text { imaging in bacterium } \\
\text { Caulobacter crescentus }\end{array}$ & $\begin{array}{l}\text { HU is the most abundant } \\
\text { nucleoid-associated Protein } \\
\text { (NAP). HU2-eYFP can be made } \\
\text { to blink on and off to achieve } \\
\text { SR imaging }\end{array}$ & $\begin{array}{l}\text { HU is slightly clustered } \\
\text { throughout the swarmer and } \\
\text { stalked stages of the cell cycle } \\
\text { but more highly clustered in } \\
\text { predivisional cells }\end{array}$ & {$[65]$} \\
\hline $\begin{array}{l}\text { To study the distributions of } \\
\text { NAPs in live Escherichia } \\
\text { coli cells }\end{array}$ & $\begin{array}{l}\text { STORM in live cells }+3 \mathrm{C} \\
\text { in living } E \text {. coli cells. H-NS is } \\
\text { global transcriptional silencer }\end{array}$ & $\begin{array}{l}\text { Four NAPs-HU, Fis, IHF, and } \\
\text { StpA-were largely scattered } \\
\text { throughout the nucleoid }\end{array}$ & $\begin{array}{l}\text { H-NS forms two compact } \\
\text { clusters per chromosome and } \\
\text { plays key role in global } \\
\text { chromosome organization in } \\
\text { bacteria }\end{array}$ & {$[66]$} \\
\hline $\begin{array}{l}\text { How to label protein with } \\
\text { an organic fluorophore }\end{array}$ & (d)STORM in living HeLa cells & $\begin{array}{l}\text { dSTORM of histone H2B } \\
\text { proteins using TMP chemical } \\
\text { tag for genetic encoding with } \\
\text { photostable fluorophores }\end{array}$ & $\begin{array}{l}\text { Live-cell SR imaging with } \\
\text { trimethoprim conjugates. Cells } \\
\text { were stained using } 2.5 \times 10^{-8} \mathrm{M} \\
\text { TMP ATTO655 for } 1 \text { hour }\end{array}$ & {$[67]$} \\
\hline Develop more chemical tags & $\begin{array}{l}\text { dSTORM + standard chemical } \\
\text { tags. } 4 \text { eukaryotic cell lines: } \\
\text { HeLa, COS- } 7 \text {, mouse } 3 \text { T3 and } \\
\text { C2C12 cells }\end{array}$ & $\begin{array}{l}\text { SNAP-Cell } 505 \text { (rhodamine } \\
\text { green) \& TMR-Star. Transfected } \\
\text { cells with plasmids coding } \\
\text { for histone H2B-SNAP- } \\
\text { tag fusion proteins }\end{array}$ & $\begin{array}{l}\text { Labeling efficiency depends on } \\
\text { cell type. SNAP-Cell 505: not } \\
\text { suitable to stain } 3 \text { T3 \& C2C12 } \\
\text { cell nuclei. TMR: well-suited } \\
\text { to stain nuclear proteins }\end{array}$ & {$[68]$} \\
\hline $\begin{array}{l}\text { How to develop binding- } \\
\text { activated SRM? }\end{array}$ & $\begin{array}{l}\text { BALM (resolution: } \sim 14 \mathrm{~nm} \text { ). } \\
\text { Fixed } E \text {. coli cells }\end{array}$ & $\begin{array}{l}\text { Two different DNA-binding } \\
\text { dyes to visualize the } \\
\text { organization of the bacterial } \\
\text { chromosome }\end{array}$ & $\begin{array}{l}\text { BALM is based on the } \\
\text { localization of individual } \\
\text { binding events, with spatial } \\
\text { sampling } 1 / \mathrm{nm}\end{array}$ & {$[56]$} \\
\hline $\begin{array}{l}\text { How to develop DNA- } \\
\text { intercalating dyes for SR } \\
\text { imaging? }\end{array}$ & $\begin{array}{l}\lambda \text {-DNA }+ \text { SRM. Immobilized } \\
\lambda \text {-DNA (is labeled with YO- } \\
\text { PRO-1 or YOYO-1) }\end{array}$ & $\begin{array}{l}\text { Blinking can be induced in } \\
\text { the DNA-intercalating } \\
\text { dimeric dye YOYO-1 in } \\
\text { combination with a reducing } \\
\text { buffer }\end{array}$ & $\begin{array}{l}\text { Both YO-PRO-1 and YOYO-1 } \\
\text { can be used in SR imaging, in } \\
\text { which photoswitching reactions } \\
\text { or blinking can be induced }\end{array}$ & {$[69]$} \\
\hline
\end{tabular}




\begin{tabular}{|c|c|c|c|c|}
\hline \multirow{3}{*}{ Goal } & & & \multicolumn{2}{|l|}{ (Continued) } \\
\hline & \multicolumn{2}{|c|}{ Method } & \multirow{2}{*}{ Conclusion } & \multirow{2}{*}{ Ref } \\
\hline & SRM \& cell types used & Experimental conditions & & \\
\hline $\begin{array}{l}\text { How to develop COMBO- } \\
\text { FISH (COMBinatorial } \\
\text { Oligo FISH)? }\end{array}$ & $\begin{array}{l}\text { COMBO-FISH + SPDM. Two } \\
\text { cell lines: human epithelial cells } \\
\text { (AG-11132) \& Peripheral blood } \\
\text { lymphocyte }\end{array}$ & $\begin{array}{l}\text { Use bioinformatical approach } \\
\text { for probe set design. Probes } \\
\text { are Peptide Nucleic Acids- } \\
\text { synthetic DNA analogues } \\
\text { with neutral backbone }\end{array}$ & $\begin{array}{l}\text { COMBO-FISH is developed in } \\
\text { this paper. Alexa488-labeled } \\
\text { PNAs has reversible photo- } \\
\text { bleaching (blinking between } \\
\text { dark and bright state) }\end{array}$ & [70] \\
\hline $\begin{array}{l}\text { How to image specific } \\
\text { repetitive DNA such as } \\
\text { DYZ2? }\end{array}$ & $\begin{array}{l}\text { FISH + SPDM. Human diploid } \\
\text { fibroblast cells VH7 }\end{array}$ & $\begin{array}{l}\text { Example of target DNA: } \\
\text { DYZ2, which is located in } \\
\text { heterochromatin region on } \\
\text { human chrom. Yq12 }\end{array}$ & $\begin{array}{l}300-700 \text { single-probe molecules } \\
\text { were resolved in individual } \\
\text { chromatin domains with } \\
500 / \mu \mathrm{m}^{2} \text { density }\end{array}$ & [71] \\
\hline $\begin{array}{l}\text { How to visualize maternal } \\
\text { and paternal homologous } \\
\text { chromosomes? }\end{array}$ & $\begin{array}{l}\text { SNPs }+ \text { Oligo-paint probes }+ \\
\text { STORM }+3 \text { D FISH } \\
\text { Mammalian WI-38 \& } \\
\text { Drosophila clone cells were } \\
\text { used }\end{array}$ & $\begin{array}{l}\text { (i) In situ visualization of } \\
\text { single-copy regions in genome } \\
\text { (ii) Oligopaint probes are } \\
\text { bioinformatically designed }\end{array}$ & $\begin{array}{l}\text { (i) SNPs to distinguish maternal \& } \\
\text { paternalhomologous } \\
\text { chromosomes. (ii) The secondary } \\
\text { oligonucleotides (oligos) to } \\
\text { produce and enhance } \\
\text { fluorescent signals }\end{array}$ & {$[72]$} \\
\hline
\end{tabular}

only less than ten frames are needed to record different polarization information for one SPoD super-resolution frame. Total imaging time of SPoD is greatly reduced to even less than $1 \mathrm{~s}$. Furthermore, a decent spatial resolution of less than $50 \mathrm{~nm}$ is achieved and several periods of polarization of modulation can be performed to enhance signal-to-noise ratio via lock-in effect. So far there is no application of SPoD in 3D genome structure yet. We used SPoD to observe GFP labelled septin protein CDC12, which shows a finer structure and higher orientation uniformity factor than that in conventional wide-field based images [73]. This new technology can be used to study not only the structure of membrane proteins and nuclear pore complex, one of the key organizers of genome structure, but also the dynamics (especially the rotation information) of these proteins.

\section{Structured illumination microscopy (SIM)}

Although it can achieve high spatial resolution, localization super-resolution microscopy has several limits. One is that it is a TIRF-based technology (Total Internal Reflection Fluorescence, TIRF), therefore the excitation is restricted largely to the $\sim 100 \mathrm{~nm}$ of the superficial layer of the cell. This makes it difficult to be applied to disperse interphase chromatin, as the thickness of chromosome is $\sim 500 \mathrm{~nm}$, which is $\sim 5 \times$ thicker than accessible. The other is acquisition time which typically lasts several minutes - traditional PALM/STORM relies on (tens of) thousands of individual images to achieve an SR image, which typically takes several minutes or more. Acquisition time largely hindered LSRM technique from gaining more attention to study genome structure. Instead, SIM, which works through frequency modulation to achieve 100-nm resolution, is more useful to investigate chromatin structure in cell nuclei for live cell study (See Figure 2).

SIM has been used to study peripheral nuclear pore complex and nuclear lamina [49], Sox2 binding sites [74], and the functional organization difference between transcriptionally active CTs and Barr body [75]. 3DSIM and 3D-FISH can be combined to show that DNA sequences within the same TAD colocalized, therefore, interacted more frequently than those in different TADs [76], and that chromatin decompacted in some key genes which are important for differentiation and these genes migrated to nucleus center during embryonic development [77].

\section{STED microscopy}

STED microscopy creates super-resolution image by selectively deactivating fluorophores, to minimize illumination area at focal point and to enhance the achievable resolution in a given system. As a deterministic functional technique, STED was firstly developed in 1994 [47], and was first experimentally demonstrated in 1999 [48]. STED exploits the non-linear response of common fluorophores to improve the resolution, differing from PALM/STORM, which is a stochastic functional technique and use math model to reconstruct sub-diffraction limit.

The super-resolution of STED is obtained by overlaying excitation laser and depletion laser to achieve an optical "sculpting" of the point spread function (PSF). To create a PSF narrower than the diffraction limit, a Gaussian beam was employed for excitation and a donut beam for de-excitation. The depletion laser beam is introduced into the light path to render a "donut" shape PSF, which is aligned and overlaid with the excitation 
beam. By increasing the depletion laser power the size of the donut hole where normal fluorescence process occurs decreases [78-80]. STED owns two major advantages over SIM and PALM/STORM: (i) It is purely optical resolution improvement without post-processing required; and (ii) STED has the same capability of optical sectioning as confocal microscope does (Figure 2).

The high power density requirement of donut beam (in $\mathrm{GW} / \mathrm{cm}^{2}$ level) of STED makes it difficult to be applied in probing the chromatin structure in living cells so far. Correlative STED/EM and correlative PALM/EM were employed to observe H2B localization in C. elegans with nanoscale resolution [81], and to detect the localization of HDAC1(histone deacetylases) [82].

\section{Light sheet super resolution microscopy}

Wide field microscopy obtains an image with excitation through the sample, which works very well with thin specimen. But for thick samples, photons outside of the focus plane will severely blur the image. Confocal microscope can block the light out of foci region, but the sample has to be illuminated during the stack imaging, leading to excessively photobleaching. These issues are circumvented by light sheet microscopy, in which the excitation and imaging are through different objectives perpendicular to each other (Figure 3). The illuminated sheet plane is imaged from the top, and the sheet can move up and down (or to rotate the sample) to form volumetric imaging.

\section{Reflected light sheet microscopy (RLSM)}

Single protein in living cells, especially protein in the nucleus, requires high sensitivity to render its localization, which is a big challenge for traditional microscopes. Gebhardt et al. developed RLSM to allow selective plane illumination to go through the nucleus of living mammalian cell using two high numerical aperture objectives $[84,85]$. RLSM can generate a very thin light sheet cutting inside the cell, thus facilitates the visualization of the spatial organization of RNA polymerase IImediated transcription inside the nucleus of mammalian cell. Previously, the physical size of the high NA objectives prohibits them from being used in light sheet microscopy, as they collides before reaching the field of view. In RLSM, parallel to imaging plane and close to sample surface, a thin light sheet is obtained by reflecting an elliptical beam of laser incident from the top by $45^{\circ}$ with an AFM cantilever as reflective mirror (see Figure 3 ). With RLSM and two-color single-molecule imaging, the DNA-bound fraction of glucocorticoid receptor (GR) was observed/measured, and different modes of the DNA binding of GR were resolved. Furthermore, the combination of reflected light-sheet illumination with SR microscopy allows users to count biomolecules with the accuracy of single copy, in order to understand the spatial distribution and organization of RNA polymerase II and chromatins $[84,85]$.

Light sheet Bayesian localization superresolution microscopy

The key points for localization super-resolution microscopy are (i) a high signal/noise ratio and (ii) the amount of single molecule events in one image frame. But many subcellular structures in human embryonic cells' nuclei, for example the heterochromatin which plays a vital role in the epigenetic regulation of gene expression, need to be monitored with high spatial resolution in deep position in cell nucleus. Therefore, these subcellular structures cannot be obtained by localization super-resolution microscopy only. Light sheet illumination can enhance SNR for single molecule SR imaging in nucleus. A light sheet Bayesian microscope based on a prism-coupled light-sheet setup [83] was developed to render deep-cell sub-diffraction imaging of heterochromatins in human embryonic stem living cells.

\section{Lattice light-sheet microscopy(LLSM)}

To address the limitation that traditional SR microscope can only be used for very limited temporal durations, a new microscope named Lattice Light-sheet Microscope (LLSM) was developed which uses ultrathin light sheets derived from two-dimensional (2D) optical lattices (Figure 4) [86]. For LLSM, the high axial resolution, negligible photobleaching and negligible background outside of the focal plane were obtained by the thinness of the sheet, while the simultaneous illumination of the entire field of view renders imaging at the rate of hundreds of planes per second even with the extremely low peak excitation intensities.

Either by implementing SIM super-resolution technique mentioned above, or by dithering the lattice to achieve a uniform light sheet illumination, one can image cells and small embryos in 3D fashion with decent spatial and temporal resolution.

LLSM was used to image TagRFP-H2B highlighted chromosomes, at five different stages during the division of a single HeLa cell [86]. The super-resolution imaging of chromosomes, mitochondria and ER in dividing LLCPK1 cells indicates that LLSM is a very promising tool to image, in 3D fashion, the fast dynamic processes in vivo in cell nuclei, due to its noninvasiveness, speed, and high spatial resolution. 


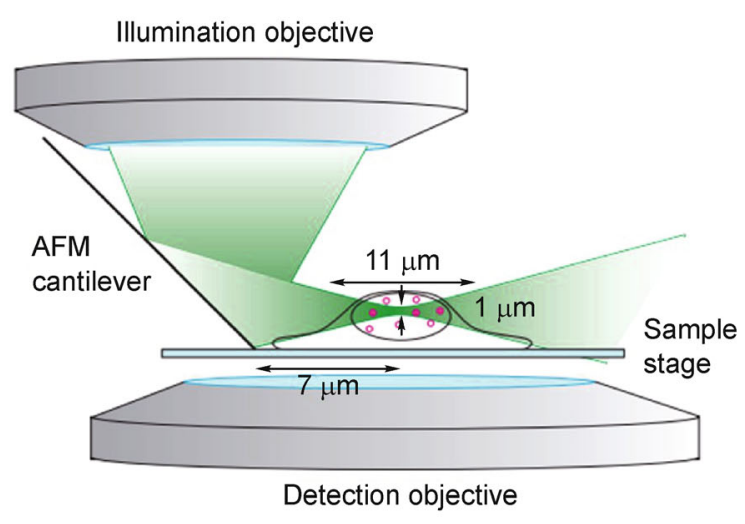

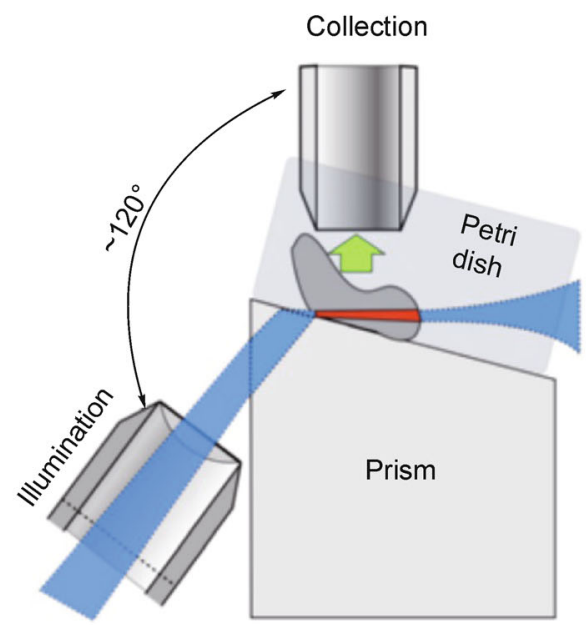

Figure 3. Diagram of light sheet super-resolution microscopes for nucleus imaging. (A) Reflected light-sheet microscopy (RLSM). (B) Prism-coupled light-sheet Bayesian microscopy (LSBM). The image was Adapted from [83] with permission.

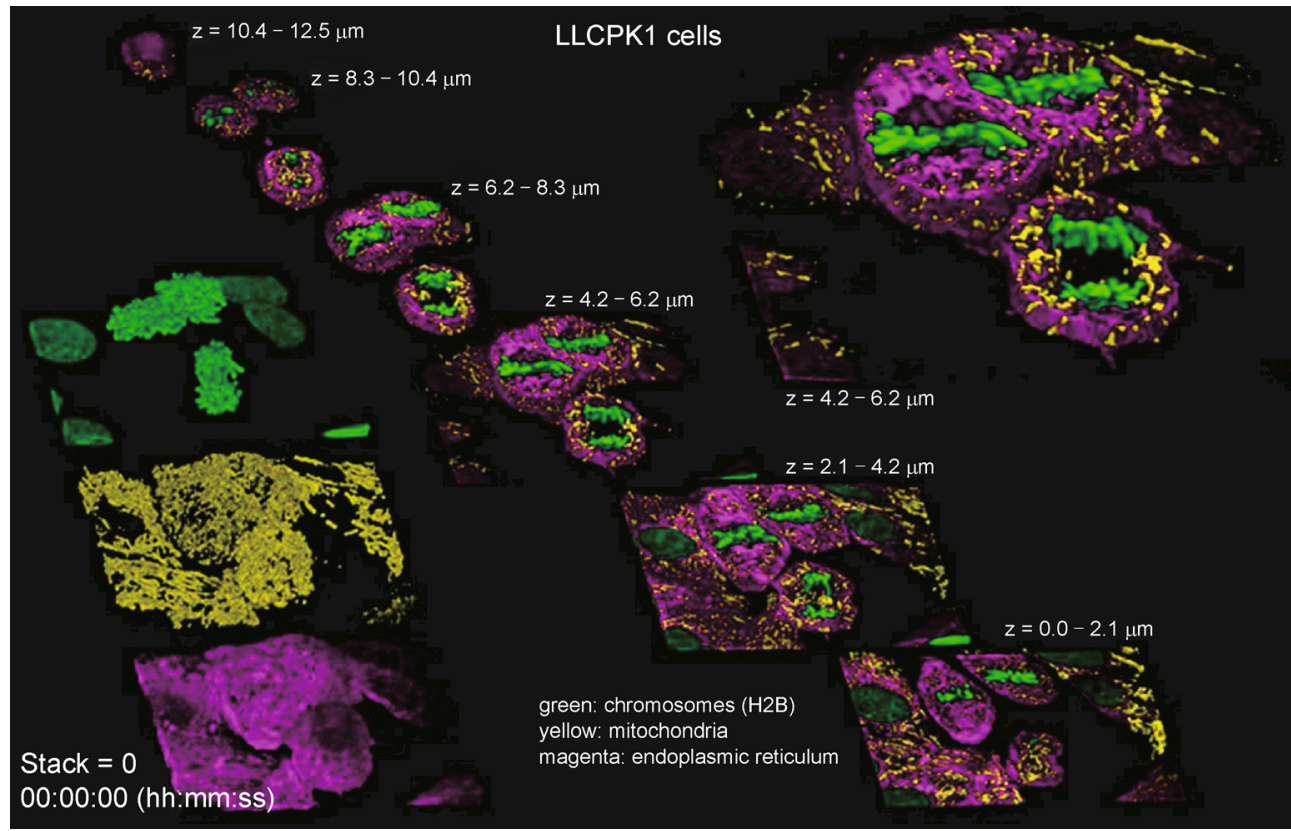

Figure 4. Imaging of chromosomes (green, mCherry-H2B), mitochondria (yellow, mitotracker-deep red), and ER (magenta, mEmerald-calnexin) in a field of dividing LLC-PK1 cells, using Lattice Light-sheet Microscopy. The image was adapted from [86] with permission.

\section{Trade-offs: Generating the best super- resolution images}

The number of SR technologies is booming so quickly that it is quite difficult for microscopy experts to keep up following the update. Therefore, it also challenges biology scientists. A comparison of localization nanoscopy, SIM and STED is shown in Table 2. In experimental practice, we need to balance some features of special super resolution modalities. Factors such as lateral resolution/axial resolution, temporal resolution, imaging depth, dyes, post-processing requirements, 


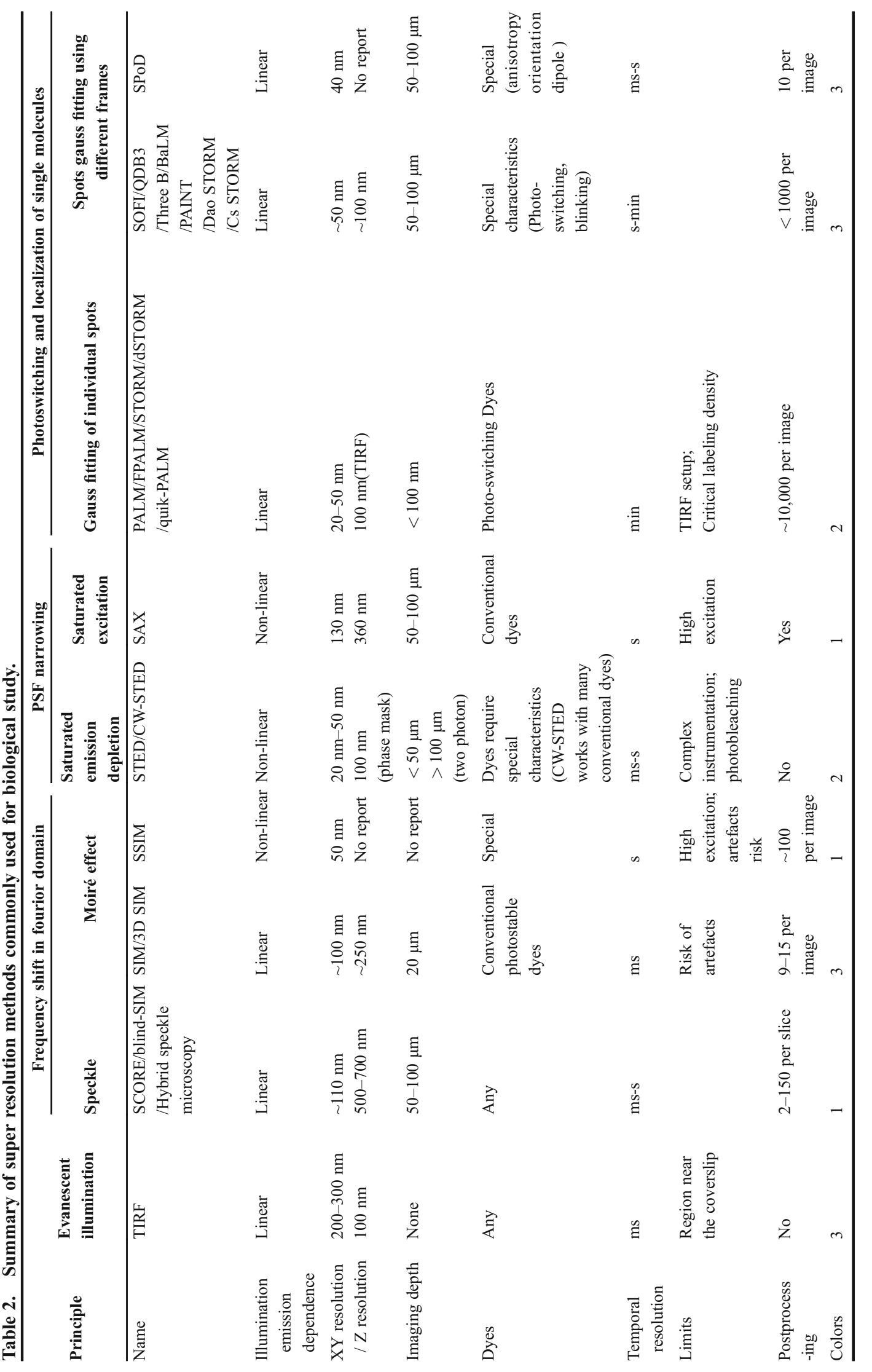


colors, artifacts, should be taken into consideration(Table 2). Also, one of the keys to obtain super-resolution images with good quality lies in the labeling with the respective fluorescent probes. At present, there is no super resolution technology can address everything well, so we have to choose the one which matches experimental requirements with special probes, such as organic dyes, fluorescence proteins, QDs, and so on. In any case, faced with the array of possible techniques, we will have to trade off the merits and drawbacks of each SR technology, by selecting the essence and abandoning the dross, in order to get the best super-resolution images for each unique project.

\section{THE DEVELOPMENT OF QUANTITATIVE METHODS BASED ON 3C-BASED TECHNIQUES}

In higher eukaryotes, gene transcription is frequently regulated through the communication of regulatory elements between promoters and enhancers or terminators $[87,88]$, which can be located hundreds, thousands or even millions of base pairs away from each other along the linear chromatins. How these regulatory elements communicate with their target genes is largely unknown.

Although many advances in imaging methods and microscopes were made during the last several decades, these methods are not able to offer genome-wide positioning information of chromatins. For example, FISH is visually compelling but generally limited to looking at the locations of a few specific targets in a few cells, although recent probe developments based on massively parallel custom oligonucleotide synthesis have expanded the scope and scale of sequences that can be analyzed in each hybridization reaction [89].

Biochemical methods, such as 3C-based techniques, complemented the imaging approach, by indicating that TADs or sub-TADs containing co-regulated clusters of genes and chromatin interactions present a non-random organizational genome structure. Even though existing imaging and these molecular mapping methods can provide us with a large deal of knowledge about genome spatial organization, computational models and quantitative data analysis are still very necessary to analyze the data produced from $3 \mathrm{C}$-based techniques, and to evaluate and simulate the three dimensional conformation of the genome. At present, three methods were developed to identify TADs in Hi-C data: HiCseg [90], Directionality Index (DI) method [9] and CHDF [91].

\section{Directionality Index (DI)}

Ren et al. considered that loci in upstream portion of a topological domain are highly biased towards interacting downstream, and downstream loci are highly biased towards interacting upstream. They constructed a chisquared test statistic called Directionality Index, which is a measure of the difference along a chromosome between upstream and downstream interactions [9]. The null hypothesis for DI is that each bin is equally likely to interact with the regions upstream and downstream of it. Hidden Markov model (HMM) was used to find "true" hidden directionality bias. The hidden states are "Upstream Bias", "Downstream Bias" or "No Bias". Baum-Welch algorithm was used to estimate parameters of transition and emission, Forward-backward algorithm was used to calculate posterior marginal, and Akaike information criterion to avoid overfitting. Only regions which have a median posterior marginal probability $\geqslant 0.99$ or at least $80 \mathrm{~kb}$ long were considered as domains [9].

\section{HiCseg}

For all domains, HiCseg method supposes that all interdomain contact intensities are independent random variables with the same distribution, whereas all intra-domain contact intensities are independent random variables, which has a distribution with specified parameters [90]. Poisson, Gaussian, or negative binomial distributions were used to model the contact intensities. The normalized Hi-C data was modelled by Gaussian distribution and raw Hi-C data by Poisson or negative binomial distributions. Variance was assumed to be constant for all kinds of contact intensities in Gaussian model. Domains were identified by maximizing the likelihood, and optimal solutions were found by dynamic programming [90].

\section{CHDF}

CHDF is to call Hi-C domains based on clustering. Hi-C interaction matrix was decomposed to three kinds of regions: (i) domain regions, (ii) the regions between two adjacent domains and (iii) the residuals. Each region was considered as a cluster and the sum-of-squared-error criterion was used for clustering. CHDF not only minimized the sum-of-squared-error criterion, but also emphasized the difference value of the average interaction intensity between domain regions and the regions between two adjacent domains. Thereafter, a penalty term was used to find domains where the Hi-C interaction intensity is much higher than the regions between two adjacent domains. Dynamic programming was employed to find the optimal solutions of domains [91].

\section{The comparison of these three methods}

CHDF, Direction Index and HiCseg methods were 


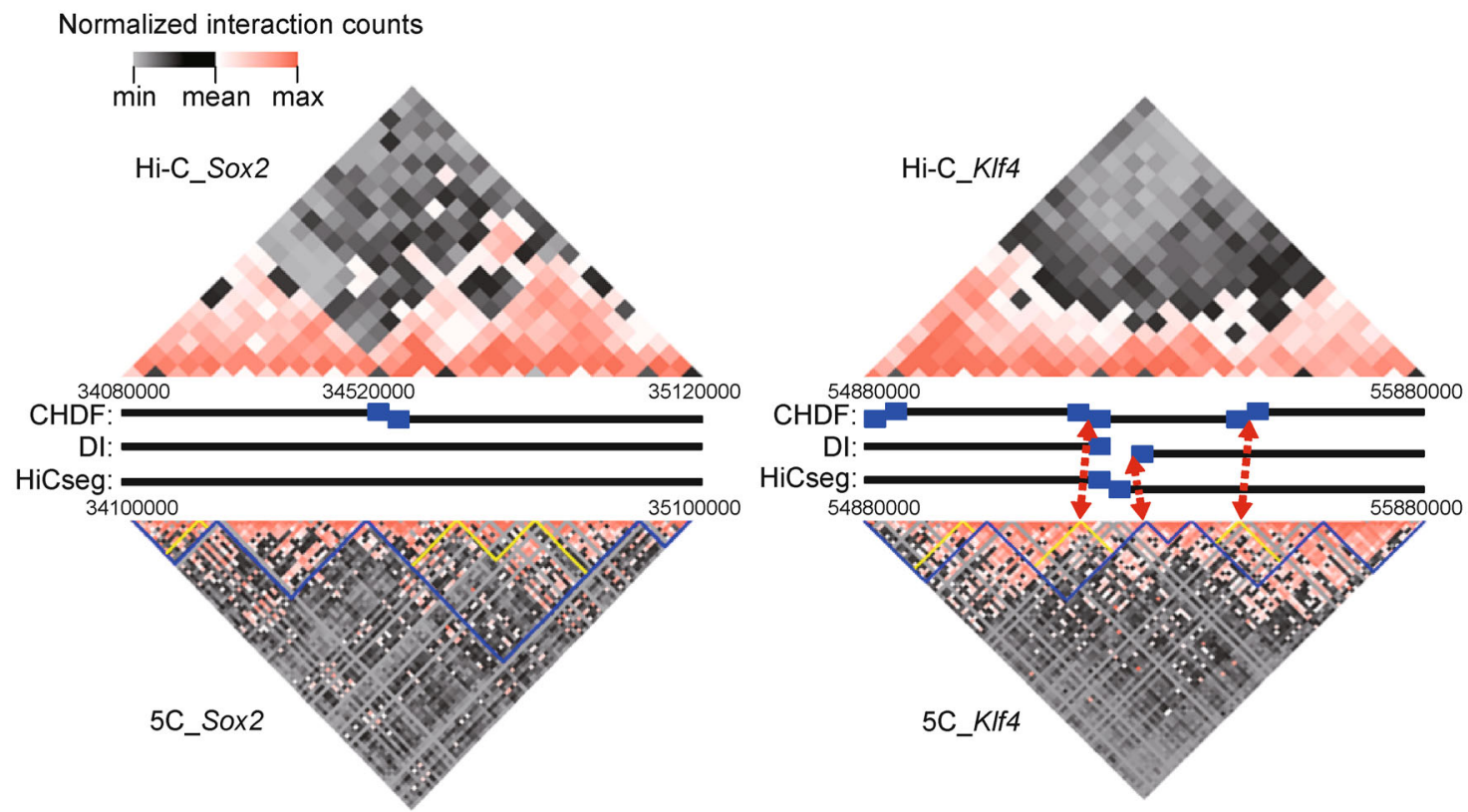

Figure 5. Comparison of three methods (Direction Index, HiCseg and CHDF) using 5C data, boundaries and domains around gene Sox 2 and KIf4 in mouse ES cell. Top: the chromatin interactions in Hi-C data after normalization. Middle: blue bars were the domain borders identified using three different methods (The border width was bin size of $40 \mathrm{~kb}$ ). Bottom: the matrix of $5 \mathrm{C}$ interactions, with bin size of $10 \mathrm{~kb} .5 \mathrm{C}$ domains were the lines marked in yellow and blue with different resolution. If a Hi-C border can be aligned to a $5 \mathrm{C}$ domain border, then a red dash line with arrows was used to connect these two borders. In KIf4 gene region, CHDF identified three borders and two of them can be aligned to the borders called by $5 \mathrm{C}$ data. The only border that cannot be aligned was too close to the beginning of $K I f 4$ gene region, which lacks upstream $5 \mathrm{C}$ data. In contrast, DI method identified just two borders of which only one border can be aligned, while HiCseg method identified only one border which cannot be aligned at all. Reproduced from [91].

systematically compared (Figure 5) on datasets of human IMR90 and mouse ES cell lines [9]. The other datasets tested include higher resolution map of $\mathrm{Hi}-\mathrm{C}$ data, synthetic Hi-C data, 5C data [92], histone modification marks, cis-eQTLs and CTCF binding sites.

First, for simulated data of which the positions of domains were known, the results calculated by CHDF method performed low false discovery rate and high sensitivities among three methods.

Second, 5C is a 3C-based method which could provide chromatin contact maps with higher resolution in specific chromatin regions, therefore has more potential to reflect finer chromatin structure. Domains called by 5C data were used to evaluate the Hi-C domains called by three methods. CHDF can identify chromatin structure at smaller scale [91], and domains called by CHDF were consistent with 5C domains [91].

Third, the insulator binding protein CTCF is important to maintain chromatin structure $[9,93]$. Combining with CTCF, active histone modification marks define TAD boundaries which lead them enriched on topological boundary regions [9]. Latest study showed that cis-eQTLs were also significantly enriched on the regions genomically close to TAD boundaries [94].

Last but not the least, the robustness to technical noise was measured by the consistence of the domains called on sub-sampling data. The robustness to biological noise was measured by the consistence of the domains called on biological replicates. HiCseg performed the best to resist technical noise in these three methods, while CHDF the best to resist biological noise [91]. Furthermore, CHDF has some parameters to limit the size and number of domains when finding the optimal solution, in order to reduce computational cost [91].

\section{Chromatin structure prediction tools}

The prediction of $3 \mathrm{D}$ genome structures enables scientists to get a visual insight about the spatial positioning of some genomic regions and the distribution of epigenetic signals $[43,95,96]$. Generally, two types of computational approaches are adopted to predict the three dimensional structure of the genome [97]: (i) "Direct approaches" that try to design a polymer model that can explain the 
Table 3. Summary of some Hi-C-based 3D genome prediction algorithms.

\begin{tabular}{lllll}
\hline Method & Frequency assumption & Inference method & Type & Principle \\
\hline $\begin{array}{l}\text { ChromSDE [101] } \\
\text { Pastis [102] }\end{array}$ & $d_{i j}=f_{j}^{-a}$ & Semi-definite programming & Consensus & No preprocessing needed \\
MCMC5C [103] & Poisson & Maximum likelihood & Consensus & No preprocessing needed \\
Gaussian & MCMC-Gaussian & Ensemble & $\begin{array}{l}\text { Models the frequency } \\
\text { noise }\end{array}$ \\
ShRec3D [104] & Shortest-path & MDS & Consensus & To enforce reliable \\
MBO [105] & Shortest-path & Manifold optimization & Consensus & $\begin{array}{l}\text { To enforce reliable } \\
\text { interactions }\end{array}$ \\
BACH [106] & Poisson & & & Bias incorporation \\
Bau et al. [107] & $d_{i j}=1 /\left(z-\right.$ score $\left.\left(f_{i j}\right)\right)$ & Baysian- MCMC & Consensus & Restraining oscillators \\
Wang et al. [108] & $d_{i j}=f_{i j}^{-a}$ & IMP & Ensemble & To minimize polymer \\
& & Bayesian & Ensemble & chain energy
\end{tabular}

observed data, and (ii) "inferential approaches" that start from the data and try to find the spatial 3D configuration that better fits the observed interaction frequencies.

One highly debatable model among the direct approaches is the Strings and Binders Switch (SBS) model developed by Barbieri et al. [98]. In the SBS model the authors started from the observation of the variability of Hi-C power-law exponent $(0.9 \sim 1.7)$ between different cell-types and species. The authors proposed a unified polymer model in which the equilibrium state of a chromatin is affected by the concentration of diffused proteins. Some scientists argued that simulations could be done using short polymers [99] while the authors claimed that long polymer simulation leads to comparable results [100].

However, with the increasing availability of $3 \mathrm{C}$-based data, such as 5C and Hi-C data, many inferential computational methods were developed recently (For the summary of some of these methods, see Table 3). These inferential approaches generally are composed of two steps.

\section{Distance matric construction}

First, the contact map needs to be converted from the frequency space to Euclidian distance space. Methods, such as in ChromSDE [101] and Pastis [102], consider the distance to anti-correlate with the frequency $d_{i j}=f_{i j}^{-a}$. To model the uncertainty of the data, MCMC5C [103] supposed that the observed frequencies were sampled from a Gaussian distribution. However, as the frequency inversion method led to mingled values for small frequency, recent algorithms such as ShRec3D [104] or MBO [105] adopted a short-path strategy in which the distance between two points is equal to the length of the shortest-path separating them. The benefits of this approach are twofold, (i) removing the effect of noisy interactions and (ii) enabling the competition of missing values in the frequency matrix.

3D model prediction

Two diverging strategies are used for the prediction of 3D chromatin structure. A set of methods predict a "global consensus 3D structure", which start from the hypothesis that the highly reliable observed frequencies represent a kind of shared structure among the cell population. To infer this structure, different methods are adopted. Some methods, such as ChromSDE and shRec3D, optimize multi-dimensional scaling problems, while others, such as BACH [106] and Pastis, optimize a statistical model in which the counts raise from Poisson distribution, with $\mathrm{BACH}$ considering the different types of bias and Pastis incorporating the bias in a global parameter.

$\mathrm{MBO}$, on the other hand, is designed for single-cell Hi-C experiments (which justifies its consensus model). It uses a manifold based optimization approach, in which the distances are constructed using weighted shortestpath. The advantage of MBO over classical MDS methods is that it needs less memory and has a faster execution time.

The dependency of contact probability on the genomic distance observed in Hi-C data indicates a cell-to-cell genomic structure variability with the increasing genomic distance. Thus, the second type of inference strategies predicts an "ensemble" of spatial conformation that captures the variability among cells. Early approach such as the one published by Bau et al. [107] uses the Integrated Modeling Platform (IMP) to generate a list of 10,000 models that fits the observed frequency constraints. More elaborated methods such as MCMC5C employ a Markov Chain Monte Carlo (MCMC) algorithm to sample ensemble structures from the posterior of the proposed statistical model. Wang et al. [108] use a 
different strategy by employing a Bayesian model that tries to find the best polymer structures which have the smallest conformational energy and can be fitted to the observed Hi-C data.

\section{Visualization tools}

With the development of $5 \mathrm{C}$ and $\mathrm{Hi}-\mathrm{C}$ technologies, an increasing amount of local and genome-wide interaction frequencies maps have been generated. These data enabled scientists to develop computational methods for the $3 \mathrm{D}$ reconstruction of the underlying chromatin structure that better fits the generated experimental 2D contact maps [102]. These 3D model inference methods use different techniques ranging from the optimization of a multi-dimensional-based functions to Bayesian models [102].

Investigators adopted many strategies to visualize and explore the predicted three-dimensional chromatin structures. The basic solution, which is largely adopted, is the direct use of 3D visualization tools designed primarily for the visualization of biomolecules such as proteins. One characteristic of biomolecules visualization software tools is the high-quality rendering capabilities which are generally stable due to the fact that they have been used and maintained by community for many years. However, one drawback of biomolecule visualization tools is that these tools were built upon the manipulation of molecules and are not well suited to fetch genomic information or to overlay different genomic signals on the top of the $3 \mathrm{D}$ structure without a lot of hacking.

To cope with these limitations, different chromatin structure visualization tools have been developed, which have different functionalities and are well adapted for chromatin 3D structure exploration. A summary of some of these tools (Table 4) are discussed below.

\section{PyMol}

PyMol is a stand-alone open-source multi-platform application widely used for biochemical structure visualization, available at http://www.pymol.org/. PyMol was first developed in 2000 by Warren Lyford DeLano [109] and then commercialized by Schroedinger, Inc from 2010.
PyMol supports a wide variety of bio-molecular 3D structure file formats such as PDB and provides very mature 3D visualization capabilities. Users have the option to use a graphical user interface or to write their own custom scripts in Python language.

Generally, the output of the existing three-dimensional chromatin prediction algorithms is in the PDB format. However, biomolecule representation format such as PDB does not store genomic information, making it challenging to overlay other genomic information onto the top of the 3D structure of chromatin without the need of additional scripting and workarounds. Nevertheless, PyMol and similar tools can be used for preliminary chromatin 3D structure visualization and they are still adopted among the chromatin structure study community.

\section{GMol}

GMol [110] builds on the top of biochemical visualization tool Jmol and was adapted to genome structure visualization. The functions introduced include genomic unit selection, sequence querying functionality, measuring distance between different units, in addition to scaling system that enables the visualization of chromosomes using different scales ranging from genome to nucleosome. GMol also defines a new file format GSS as a counter part that enables the display of chromatin structure at different scales compatible with GMol's multi-scale display system.

Users who want more functionality can write additional scripts to do some custom annotations. Despite these functionalities, GMol is still at a pre-mature stage. It can solve some of the chromatin structure visualization problems but needs improvement to enable easy overlay of different genomic data (such as ChIP-Seq signals).

\section{Genome3D}

Genome3D [111] is one of the first tools designed to solve the problem of visualizing chromatin structure in 3D fashion. It is a GUI-based C++ software that runs on the top of Windows Operating System. The 3D display in Genome3D is based on OpenGL framework. Similar to GMol, Genome3D implements a multi-scaling system

Table 4. Comparison of several popular 3D chromatin visualization tools.

\begin{tabular}{lllllll}
\hline Tool & $\begin{array}{l}\text { Specific to 3D } \\
\text { genome display }\end{array}$ & $\begin{array}{l}\text { 3D model } \\
\text { display }\end{array}$ & $\begin{array}{l}\text { Cis-interaction } \\
\text { display }\end{array}$ & $\begin{array}{l}\text { Trans-interaction } \\
\text { display }\end{array}$ & $\begin{array}{l}\text { Custom } \\
\text { annotation }\end{array}$ & $\begin{array}{l}\text { Need } \\
\text { scripting }\end{array}$ \\
\hline PyMol [109] & $\times$ & $\sqrt{ }$ & $\times$ & $\times$ & $\sqrt{ }$ & $\sqrt{ }$ \\
GMol [110] & $\sqrt{ }$ & $\sqrt{ }$ & $\times$ & $\times$ & $\times$ & $\sqrt{ }$ \\
Genome3D [111] & $\sqrt{ }$ & $\sqrt{ }$ & $\times$ & $\times$ & $\sqrt{ }$ & $\times$ \\
Tadkit & $\sqrt{ }$ & $\sqrt{ }$ & $\times$ & $\times$ & $\sqrt{ }$ & $\times$ \\
HiC-3DViewer(unpublished) & $\sqrt{ }$ & $\sqrt{ }$ & $\sqrt{ }$ & $\sqrt{ }$ & $\sqrt{ }$ & $\times$ \\
\hline
\end{tabular}


that enables the visualization of the genome at different scales. Additionally, users have the ability to import epigenetic data from UCSC Genome Database Browser and overlay it onto the $3 \mathrm{D}$ structure. However, a bottleneck is that users need to provide an openXML formatted genome that encodes different scaling information, which makes it difficult to upload custom genomes easily.

Tadkit

Tadkit (http://sgt.cnag.cat/3dg/tadkit/) is a web-based tool to visualize chromatin structure. It exploits the WebGL feature offered by HTML5 for 3D display. Investigators can overlay genomic data on the top of the 3D structure or upload their own 3D model. Different tracks are available for user to choose from, such as Genes track and some epigenetic signals. Users can also upload their own data. However, as Tadkit is still at development stage and different features will be added step by step, no final conclusion can be drawn. But it seems that more customization and display performance capabilities need to be considered in order to display larger genomes.

\section{HiC-3DViewer}

In our lab we are also interested in developing chromatin visualization tools. Recently, we developed HiC3DViewer (unpublished data), an interactive web-based chromatin visualization tool to provide an intuitive environment for investigators to do 3D exploratory analysis. It offers many functionalities missed in the previous tools and accepts simple input formats that can be created by non-professional users without scripting knowledge.

\section{CONCLUSION}

Super-resolution fluorescence microscopy is developed to fill a resolution gap not only between electron microscope and traditional fluorescence microscope, but also between "beads-on-a-string" 10-nm fiber and condensed chromatin fiber with a diameter of several hundred nanometers. These novel bioimaging methods have been employed to study the complex chromatin organization, which span several orders of magnitude to save genetic information on the mix of DNA and proteins, and to verify that organizational units, for example, domains with similar size as TADs, do exist in 3D genome [112].

However, it is challenging to employ SR microscopy to study the relationship between 3D genome organization and the regulation of gene transcription. The difficulty might stem from multiple sources: (i) SRM heavily relies on the properties of fluorophores, as single-fluorophore detection is a prerequisite for SR imaging [113]. Users need to evaluate which fluorescent probes should be used - organic dyes, fluorescent proteins, quantum dot or else. (ii) Choosing the most appropriate labelling strategy is also challenging. To study 3D genome organization, what labelling density should be chosen, for a given SR microscope? Should DNA be directly labelled, or should DNA-associated proteins such as histone be labelled? Should histones be tagged by photoswitchable fluorescent proteins, or chemical tags, or by immunostaining? (iii) Cellular states should be considered as well, such as diploid nature of individual cells, different cell cycle stages, live cell or fixed cells, embryonic stem cells or differentiated cells, and the significant difference in chromatin conformations between individual cells, etc. (iv) Which SR microscope and what algorithms should be employed to minimize the noise in images? And what kind of control or calibration is suitable - fluorescent beads, DNA origami nanopillars [114], UCNP [115], or else - for in vitro or in vivo experiment? (v) How could one combine optical microscope with electron microscope, to have a better vision about genome structure?

Though the fundamental principles behind chromatin folding and unfolding in 3D fashion during interphase are still unknown, it is clear that distal elements such as enhancers control gene regulation by physical contacts between them. Imaging methods such as FISH and SRM, and molecular biology methods such as 3C-series methods are not mutually exclusive - actually they are complemental to each other. FISH and the recently rapidly established type II clustered regularly interspaced short palindromic repeats (CRISPR) technology [116] can be used not only to visualize specific DNA fragments in cell nucleus, in fixed cells or living cells respectively, but also to verify the chromatin interactions identified by Hi$\mathrm{C}$ or other $3 \mathrm{C}$ derivatives. For example, FISH was used to visualize the colocalization of olfactory receptor allele and an enhancer element in individual neurons [117]. CRISPR/Cas9-based technology [118,119] in conjuncted with 3C derivatives, can be used to study chromatin organization $[120,121,122]$ in an elegant way. With the power of SRM, 3C-based methods and FISH/CRISPR technology are offering us more solutions to understand how the dynamics and organization of chromatin structure are functionally translated into the regulation of gene transcription, repair, and expression.

\section{ACKNOWLEDGEMENTS}

Due to the space constraints, we regret that we are unable to address the importance of all work in the field. This work is supported by National Basic Research Project (973 Program, No. 2012CB316503) and the National Natural Science Foundation of China (Nos. 31361163004 and 91019016). The authors also thank many colleagues in Prof. Michael Q. Zhang's 
laboratory and Prof. Peng Xi's laboratory who shared their enthusiasm, ideas, experimental and computational results to make this review possible.

\section{COMPLIANCE WITH ETHICS GUIDELINES}

The authors Juntao Gao, Xusan Yang, Mohamed Nadhir Djekidel, Yang Wang, Peng Xi and Michael Q. Zhang declare that they have no conflict of interest.

This article does not contain any studies with human or animal subjects performed by any of the authors.

\section{REFERENCES}

1. Alberts, B., Johnson, A., Lewis, J., Raff, M., Roberts, K. and Walter, P. (2002). Molecular Biology of the Cell New. $4^{\text {th }}$ Ed., York: Garland Science

2. Luger, K., Mäder, A. W., Richmond, R. K., Sargent, D. F. and Richmond, T. J. (1997) Crystal structure of the nucleosome core particle at $2.8 \AA$ resolution. Nature, 389, 251-260

3. Li, G. and Reinberg, D. (2011) Chromatin higher-order structures and gene regulation. Curr. Opin. Genet. Dev., 21, 175-186

4. Thakar, A., Gupta, P., Ishibashi, T., Finn, R., Silva-Moreno, B., Uchiyama, S., Fukui, K., Tomschik, M., Ausio, J. and Zlatanova, J. (2009) H2A.Z and H3.3 histone variants affect nucleosome structure: biochemical and biophysical studies. Biochemistry (Mosc.), 48, 10852-10857

5. Sahl, S. J. and Moerner, W. E. (2013) Super-resolution fluorescence imaging with single molecules. Curr. Opin. Struct. Biol., 23, 778-787

6. Yamanaka, M., Smith, N. I. and Fujita, K. (2014) Introduction to super-resolution microscopy. Microscopy, 63, 177-192

7. Doksani, Y., Wu, J. Y., de Lange, T. and Zhuang, X. (2013) Superresolution fluorescence imaging of telomeres reveals TRF2-dependent t-loop formation. Cell, 155, 345-356

8. Dekker, J., Rippe, K., Dekker, M. and Kleckner, N. (2002) Capturing chromosome conformation. Science, 295, 1306-1311

9. Dixon, J. R., Selvaraj, S., Yue, F., Kim, A., Li, Y., Shen, Y., Hu, M., Liu, J. S. and Ren, B. (2012) Topological domains in mammalian genomes identified by analysis of chromatin interactions. Nature, 485 , 376-380

10. Kalhor, R., Tjong, H., Jayathilaka, N., Alber, F. and Chen, L. (2012) Genome architectures revealed by tethered chromosome conformation capture and population-based modeling. Nat. Biotechnol., 30, 90-98

11. Lieberman-Aiden, E., van Berkum, N. L., Williams, L., Imakaev, M., Ragoczy, T., Telling, A., Amit, I., Lajoie, B. R., Sabo, P. J., Dorschner, M. O., et al. (2009) Comprehensive mapping of long-range interactions reveals folding principles of the human genome. Science, 326, 289-293

12. Zhang, Y., McCord, R. P., Ho, Y.-J., Lajoie, B. R., Hildebrand, D. G., Simon, A. C., Becker, M. S., Alt, F. W. and Dekker, J. (2012) Spatial organization of the mouse genome and its role in recurrent chromosomal translocations. Cell, 148, 908-921

13. Cremer, T. and Cremer, C. (2001) Chromosome territories, nuclear architecture and gene regulation in mammalian cells. Nat. Rev. Genet., 2, 292-301

14. Funabiki, H., Hagan, I., Uzawa, S. and Yanagida, M. (1993) Cell cycle-dependent specific positioning and clustering of centromeres and telomeres in fission yeast. J. Cell Biol., 121, 961-976

15. Mizuguchi, T., Barrowman, J. and Grewal, S. I. S. (2015)
Chromosome domain architecture and dynamic organization of the fission yeast genome. FEBS Lett., 589, 2975-2986

16. Rabl, C. (1885) Über Zelltheilung. Morphol. Jahrb., 10, 214-330

17. Jin, Q.-W., Fuchs, J. and Loidl, J. (2000) Centromere clustering is a major determinant of yeast interphase nuclear organization. J. Cell Sci., 113, 1903-1912

18. Cremer, T. (2013) Von der Zellenlehre zur Chromosomentheorie: Naturwissenschaftliche Erkenntnis und Theorienwechsel in der frühen Zell- und Vererbungsforschung. Berlin: Springer-Verlag

19. Hochstrasser, M., Mathog, D., Gruenbaum, Y., Saumweber, H. and Sedat, J. W. (1986) Spatial organization of chromosomes in the salivary gland nuclei of Drosophila melanogaster. J. Cell Biol., 102, $112-123$

20. Zickler, D. and Kleckner, N. (1998) The leptotene-zygotene transition of meiosis. Annu. Rev. Genet., 32, 619-697

21. Jin, Q., Trelles-Sticken, E., Scherthan, H. and Loidl, J. (1998) Yeast nuclei display prominent centromere clustering that is reduced in nondividing cells and in meiotic prophase. J. Cell Biol., 141, 21-29

22. Noguchi, J. and Fukui, K. (1995) Chromatin arrangements in intact interphase nuclei examined by laser confocal microscopy. J. Plant Res., 108, 209-216

23. Wilkie, G. S., Shermoen, A. W., O'Farrell, P. H. and Davis, I. (1999) Transcribed genes are localized according to chromosomal position within polarized Drosophila embryonic nuclei. Curr. Biol., 9, 1263 1266

24. Bolzer, A., Kreth, G., Solovei, I., Koehler, D., Saracoglu, K., Fauth, C., Müller, S., Eils, R., Cremer, C., Speicher, M. R., et al. (2005) Three-dimensional maps of all chromosomes in human male fibroblast nuclei and prometaphase rosettes. PLoS Biol., 3, e157

25. Boyle, S., Gilchrist, S., Bridger, J. M., Mahy, N. L., Ellis, J. A. and Bickmore, W. A. (2001) The spatial organization of human chromosomes within the nuclei of normal and emerin-mutant cells Hum. Mol. Genet., 10, 211-219

26. Küpper, K., Kölbl, A., Biener, D., Dittrich, S., von Hase, J., Thormeyer, T., FieglerH., Carter, N. P., Speicher, M. R., Cremer, T., et al. (2007) Radial chromatin positioning is shaped by local gene density, not by gene expression. Chromosoma, 116, 285-306

27. Croft, J. A., Bridger, J. M., Boyle, S., Perry, P., Teague, P. and Bickmore, W. A. (1999) Differences in the localization and morphology of chromosomes in the human nucleus. J. Cell Biol., $145,1119-1131$

28. Fraser, J., Williamson, I., Bickmore, W. A. and Dostie, J. (2015) An overview of genome organization and how we got there: from FISH to Hi-C. Microbiol. Mol. Biol. Rev., 79, 347-372

29. Kreth, G., Finsterle, J., von Hase, J., Cremer, M. and Cremer, C. (2004) Radial arrangement of chromosome territories in human cell nuclei: a computer model approach based on gene density indicates a probabilistic global positioning code. Biophys. J., 86, 2803-2812

30. Bridger, J. M., Boyle, S., Kill, I. R. and Bickmore, W. A. (2000) Remodelling of nuclear architecture in quiescent and senescent human fibroblasts. Curr. Biol., 10, 149-152

31. Mehta, I. S., Amira, M., Harvey, A. J. and Bridger, J. M. (2010) Rapid chromosome territory relocation by nuclear motor activity in response to serum removal in primary human fibroblasts. Genome Biol., 11, R5

32. Nagele, R., Freeman, T., McMorrow, L. and Lee, H. Y. (1995) Precise spatial positioning of chromosomes during prometaphase: evidence for chromosomal order. Science, 270, 1831-1835

33. Nagele, R. G., Freeman, T., Fazekas, J., Lee, K. M., Thomson, Z. and 
Lee, H. Y. (1998) Chromosome spatial order in human cells: evidence for early origin and faithful propagation. Chromosoma, 107, 330-338

34. Bickmore, W. A. (2013) The spatial organization of the human genome. Annu. Rev. Genomics Hum. Genet., 14, 67-84

35. Habermann, F. A., CremerM., Walter, J., Kreth, G., von Hase, J., Bauer, K., Wienberg, J., Cremer, C., Cremer, T. and Solovei, I. (2001) Arrangements of macro- and microchromosomes in chicken cells. Chromosome Res., 9, 569-584

36. Sun, H. B. and Yokota, H. (1999) Correlated positioning of homologous chromosomes in daughter fibroblast cells. Chromosome Res., 7, 603-610

37. Gerlich, D., Beaudouin, J., Kalbfuss, B., Daigle, N., Eils, R. and Ellenberg, J. (2003) Global chromosome positions are transmitted through mitosis in mammalian cells. Cell, 112, 751-764

38. Manders, E. M., Kimura, H. and Cook, P. R. (1999) Direct imaging of DNA in living cells reveals the dynamics of chromosome formation. J. Cell Biol., 144, 813-821

39. Allison, D. C. and Nestor, A. L. (1999) Evidence for a relatively random array of human chromosomes on the mitotic ring. J. Cell Biol., $145,1-14$

40. Walter, J., Schermelleh, L., Cremer, M., Tashiro, S. and Cremer, T. (2003) Chromosome order in HeLa cells changes during mitosis and early G1, but is stably maintained during subsequent interphase stages. J. Cell Biol., 160, 685-697

41. Strickfaden, H., Zunhammer, A., van Koningsbruggen, S., Köhler, D. and Cremer, T. (2010) 4D chromatin dynamics in cycling cells: Theodor Boveri's hypotheses revisited. Nucleus, 1, 284-297

42. Umbarger, M. A., Toro, E., Wright, M. A., Porreca, G. J., Baù, D., Hong, S.-H., Fero, M. J., Zhu, L. J., Marti-Renom, M. A., McAdams, H. H., et al. (2011) The three-dimensional architecture of a bacterial genome and its alteration by genetic perturbation. Mol. Cell, 44, 252264

43. Duan, Z., Andronescu, M., Schutz, K., McIlwain, S., Kim, Y. J., Lee, C., Shendure, J., Fields, S., Blau, C. A. and Noble, W. S. (2010) A three-dimensional model of the yeast genome. Nature, 465, 363-367

44. Feng, S., Cokus, S. J., Schubert, V., Zhai, J., Pellegrini, M. and Jacobsen, S. E. (2014) Genome-wide Hi-C analyses in wild-type and mutants reveal high-resolution chromatin interactions in Arabidopsis. Mol. Cell, 55, 694-707

45. Filippova, D., Patro, R., Duggal, G. and Kingsford, C. (2014) Identification of alternative topological domains in chromatin. Algorithms Mol. Biol., 9, 14

46. Phillips-Cremins, J. E., Sauria, M. E. G., Sanyal, A., Gerasimova, T. I., Lajoie, B. R., Bell, J. S. K., Ong, C.-T., Hookway, T. A., Guo, C., Sun, Y., et al. (2013) Architectural protein subclasses shape 3D organization of genomes during lineage commitment. Cell, 153, 1281-1295

47. Hell, S. W. and Wichmann, J. (1994) Breaking the diffraction resolution limit by stimulated emission: stimulated-emission-depletion fluorescence microscopy. Opt. Lett., 19, 780

48. Klar, T. A. and Hell, S. W. (1999) Subdiffraction resolution in far-field fluorescence microscopy. Opt. Lett., 24, 954

49. Schermelleh, L., Carlton, P. M., Haase, S., Shao, L., Winoto, L., Kner, P., Burke, B., Cardoso, M. C., Agard, D. A., Gustafsson, M. G. L., et al. (2008) Subdiffraction multicolor imaging of the nuclear periphery with 3D structured illumination microscopy. Science, 320, 1332-1336

50. Hafi, N., Grunwald, M., van den Heuvel, L. S., Aspelmeier, T., Chen, J.-H., Zagrebelsky, M., Schütte, O. M., Steinem, C., Korte, M., Munk, A., et al. (2014) Fluorescence nanoscopy by polarization modulation and polarization angle narrowing. Nat. Methods, 11, 579-584

51. Cox, S., Rosten, E., Monypenny, J., Jovanovic-Talisman, T., Burnette, D. T., Lippincott-SchwartzJ., Jones, G. E. and Heintzmann, R. (2012) Bayesian localization microscopy reveals nanoscale podosome dynamics. Nat. Methods, 9, 195-200

52. Zhu, L., Zhang, W., Elnatan, D. and Huang, B. (2012) Faster STORM using compressed sensing. Nat. Methods, 9, 721-723

53. Jungmann, R., Avendaño, M. S., Woehrstein, J. B., Dai, M., Shih, W. M. and Yin, P. (2014) Multiplexed 3D cellular super-resolution imaging with DNA-PAINT and Exchange-PAINT. Nat. Methods, 11, 313-318

54. Sharonov, A. and Hochstrasser, R. M. (2006) Wide-field subdiffraction imaging by accumulated binding of diffusing probes. Proc. Natl. Acad. Sci. USA, 103, 18911-18916

55. Henriques, R., Lelek, M., Fornasiero, E. F., Valtorta, F., Zimmer, C. and Mhlanga, M. M. (2010) QuickPALM: 3D real-time photoactivation nanoscopy image processing in Image. J. Nat. Methods, 7, 339340

56. Schoen, I., Ries, J., Klotzsch, E., Ewers, H. and Vogel, V. (2011) Binding-activated localization microscopy of DNA structures. Nano Lett., 11, 4008-4011

57. Geissbuehler, S., Bocchio, N. L., Dellagiacoma, C., Berclaz, C., Leutenegger, M. and Lasser, T. (2012) Mapping molecular statistics with balanced super-resolution optical fluctuation imaging (bSOFI). Opt. Nanoscopy, 1, 1-7

58. Hu, Y. S., Nan, X., Sengupta, P., Lippincott-Schwartz, J. and Cang, H. (2013) Accelerating 3B single-molecule super-resolution microscopy with cloud computing. Nat. Methods, 10, 96-97

59. Wang, Y., Fruhwirth, G., Cai, E., Ng, T. and Selvin, P. R. (2013) 3D super-resolution imaging with blinking quantum dots. Nano Lett., 13, 5233-5241

60. Ribeiro, S. A., Vagnarelli, P., Dong, Y., Hori, T., McEwen, B. F., Fukagawa, T., Flors, C. and Earnshaw, W. C. (2010) A superresolution map of the vertebrate kinetochore. Proc. Natl. Acad. Sci. USA, 107, 10484-10489

61. Matsuda, A., Shao, L., Boulanger, J., Kervrann, C., Carlton, P. M., Kner, P., Agard, D. and Sedat, J. W. (2010) Condensed mitotic chromosome structure at nanometer resolution using PALM and EGFP- histones. PLoS One, 5, e12768

62. Bohn, M., Diesinger, P., Kaufmann, R., Weiland, Y., Müller, P., Gunkel, M., von Ketteler, A., Lemmer, P., Hausmann, M., Heermann, D. W., et al. (2010) Localization microscopy reveals expressiondependent parameters of chromatin nanostructure. Biophys. J., 99, $1358-1367$

63. Gunkel, M., Erdel, F., Rippe, K., Lemmer, P., Kaufmann, R., Hörmann, C., Amberger, R. and Cremer, C. (2009) Dual color localization microscopy of cellular nanostructures. Biotechnol. J., 4, 927-938

64. Ptacin, J. L., Lee, S. F., Garner, E. C., Toro, E., Eckart, M., Comolli, L. R., Moerner, W. E. and Shapiro, L. (2010) A spindle-like apparatus guides bacterial chromosome segregation. Nat. Cell Biol., 12, 791798

65. Lee, H. D., Lord, S. J., Iwanaga, S., Zhan, K., Xie, H., Williams, J. C., Wang, H., Bowman, G. R., Goley, E. D., Shapiro, L., et al. (2010) Superresolution imaging of targeted proteins in fixed and living cells using photoactivatable organic fluorophores. J. Am. Chem. Soc., 132, 15099-15101

66. Wang, W., Li, G.-W., Chen, C., Xie, X. S. and Zhuang, X. (2011) 
Chromosome organization by a nucleoid-associated protein in live bacteria. Science, 333, 1445-1449

67. Wombacher, R., Heidbreder, M., van de Linde, S., Sheetz, M. P., Heilemann, M., Cornish, V. W. and Sauer, M. (2010) Live-cell superresolution imaging with trimethoprim conjugates. Nat. Methods, 7, 717-719

68. Klein, T., Löschberger, A., Proppert, S., Wolter, S., van de Linde, S. and Sauer, M. (2011) Live-cell dSTORM with SNAP-tag fusion proteins. Nat. Methods, 8, 7-9

69. Flors, C. (2010) Photoswitching of monomeric and dimeric DNAintercalating cyanine dyes for super-resolution microscopy applications. Photochem. Photobiol. Sci., 9, 643-648

70. Müller, P., Schmitt, E., Jacob, A., Hoheisel, J., Kaufmann, R., Cremer, C. and Hausmann, M. (2010) COMBO-FISH enables high precision localization microscopy as a prerequisite for nanostructure analysis of genome loci. Int. J. Mol. Sci., 11, 4094-4105

71. Weiland, Y., Lemmer, P. and Cremer, C. (2011) Combining FISH with localisation microscopy: Super-resolution imaging of nuclear genome nanostructures. Chromosome Res., 19, 5-23

72. Beliveau, B. J., Boettiger, A. N., Avendaño, M. S., Jungmann, R., McCole, R. B., Joyce, E. F., Kim-Kiselak, C., Bantignies, F., Fonseka, C. Y., Erceg, J., et al. (2015) Single-molecule super-resolution imaging of chromosomes and in situ haplotype visualization using Oligopaint FISH probes. Nat. Commun., 6, 7147

73. Zhang, H., Chen, L., Yang, X., Wang, M., Jing, Z., Han, H., Zhang, M., Jin, D., Gao, J., and Xi, P. (2016) Orientation mapping superresolution with polarization demodulation. Light Sci. Appl., (Accepted)

74. Liu, Z., Legant, W. R., Chen, B.-C., Li, L., Grimm, J. B., Lavis, L. D., Betzig, E. and Tjian, R. (2014) 3D imaging of Sox2 enhancer clusters in embryonic stem cells. eLife, 3, e04236

75. Smeets, D., Markaki, Y., Schmid, V. J., Kraus, F., Tattermusch, A., Cerase, A., Sterr, M., Fiedler, S., Demmerle, J., Popken, J., et al. (2014) Three-dimensional super-resolution microscopy of the inactive $\mathrm{X}$ chromosome territory reveals a collapse of its active nuclear compartment harboring distinct Xist RNA foci. Epigenet. Chromatin, 7,8

76. Markaki, Y., Smeets, D., Fiedler, S., Schmid, V. J., Schermelleh, L., Cremer, T. and Cremer, M. (2012) The potential of 3D-FISH and super-resolution structured illumination microscopy for studies of 3D nuclear architecture: 3D structured illumination microscopy of defined chromosomal structures visualized by 3D (immuno)-FISH opens new perspectives for studies of nuclear architecture. BioEssays, 34, 412426

77. Patel, N. S., Rhinn, M., Semprich, C. I., Halley, P. A., Dollé, P., Bickmore, W. A. and Storey, K. G. (2013) FGF signalling regulates chromatin organisation during neural differentiation via mechanisms that can be uncoupled from transcription. PLoS Genet., 9, e1003614

78. Harke, B., Ullal, C. K., Keller, J. and Hell, S. W. (2008) Threedimensional nanoscopy of colloidal crystals. Nano Lett., 8, 13091313

79. Yang, X., Tzeng, Y.-K., Zhu, Z., Huang, Z., Chen, X., Liu, Y., Chang, H.-C., Huang, L., Li, W.-D. and Xi, P. (2014) Sub-diffraction imaging of nitrogen-vacancy centers in diamond by stimulated emission depletion and structured illumination. RSC Advances, 4, 1130511310

80. Xie, H., Liu, Y., Jin, D., Santangelo, P. J. and Xi, P. (2013) Analytical description of high-aperture STED resolution with $0-2 \pi$ vortex phase modulation. J. Opt. Soc. Am. A Opt. Image Sci. Vis., 30, 1640 1645

81. Watanabe, S., Punge, A., Hollopeter, G., Willig, K. I., Hobson, R. J., Davis, M. W., Hell, S. W. and Jorgensen, E. M. (2011) Protein localization in electron micrographs using fluorescence nanoscopy. Nat. Methods, 8, 80-84

82. Ascoli, C. A., Jacob, T., Crowe, S. and Heidemann, K. (2015) Localization of HDAC1 Using Super-Resolution STED Microscopy. Leica Sci.http://www.leica-microsystems.com/science-lab/localization-of-hdac1-using-super-resolution-sted-microscopy/

83. Hu, Y. S., Zhu, Q., Elkins, K., Tse, K., Li, Y., Fitzpatrick, J. A. J., Verma, I. M. and Cang, H. (2013) Light-sheet Bayesian microscopy enables deep-cell super-resolution imaging of heterochromatin in live human embryonic stem cells. Opt. Nanoscopy, 2, 7

84. Gebhardt, J. C. M., Suter, D. M., Roy, R., Zhao, Z. W., Chapman, A R., BasuS., Maniatis, T. and Xie, X. S. (2013) Single-molecule imaging of transcription factor binding to DNA in live mammalian cells. Nat. Methods, 10, 421-426

85. Zhao, Z. W., Roy, R., Gebhardt, J. C. M., Suter, D. M., Chapman, A. R. and Xie, X. S. (2014) Spatial organization of RNA polymerase II inside a mammalian cell nucleus revealed by reflected light-sheet superresolution microscopy. Proc. Natl. Acad. Sci. USA, 111, 681686

86. Chen, B.-C., Legant, W. R., Wang, K., Shao, L., Milkie, D. E., Davidson, M. W., Janetopoulos, C., Wu, X. S., Hammer, J. A., Liu, Z., et al. (2014) Lattice light-sheet microscopy: Imaging molecules to embryos at high spatiotemporal resolution. Science, 346, 1257998

87. O’Sullivan, J. M., Tan-Wong, S. M., Morillon, A., Lee, B., Coles, J., Mellor, J. and Proudfoot, N. J. (2004) Gene loops juxtapose promoters and terminators in yeast. Nat. Genet., 36, 1014-1018

88. Ansari, A. and Hampsey, M. (2005) A role for the CPF 3'-end processing machinery in RNAP II-dependent gene looping. Genes Dev., 19, 2969-2978

89. Boyle, S., Rodesch, M. J., Halvensleben, H. A., Jeddeloh, J. A. and Bickmore, W. A. (2011) Fluorescence in situ hybridization with highcomplexity repeat-free oligonucleotide probes generated by massively parallel synthesis. Chromosome Res., 19, 901-909

90. Lévy-Leduc, C., Delattre, M., Mary-Huard, T. and Robin, S. (2014) Two-dimensional segmentation for analyzing Hi-C data. Bioinformatics, 30, i386-i392

91. Wang, Y., Li, Y., Gao, J. and Zhang, M. Q. (2015) A novel method to identify topological domains using Hi-C data. Quant. Biol., 3, 8189

92. Dostie, J., Richmond, T. A., Arnaout, R. A., Selzer, R. R., Lee, W. L., Honan, T. A., Rubio, E. D., Krumm, A., Lamb, J., Nusbaum, C., et al. (2006) Chromosome Conformation Capture Carbon Copy (5C): a massively parallel solution for mapping interactions between genomic elements. Genome Res., 16, 1299-1309

93. Handoko, L., Xu, H., Li, G., Ngan, C. Y., Chew, E., Schnapp, M., LeeC. W. H., Ye, C., Ping, J. L. H., Mulawadi, F., et al. (2011) CTCFmediated functional chromatin interactome in pluripotent cells. Nat. Genet., 43, 630-638

94. Duggal, G., Wang, H. and Kingsford, C. (2014) Higher-order chromatin domains link eQTLs with the expression of far-away genes. Nucleic Acids Res., 42, 87-96

95. Jhunjhunwala, S., van Zelm, M. C., Peak, M. M., Cutchin, S., Riblet, R., van Dongen, J. J. M., Grosveld, F. G., Knoch, T. A. and Murre, C. (2008) The 3D structure of the immunoglobulin heavy-chain locus: 
implications for long-range genomic interactions. Cell, 133, 265-279

96. Nagano, T., Lubling, Y., Stevens, T. J., Schoenfelder, S., Yaffe, E., Dean, W., Laue, E. D., Tanay, A. and Fraser, P. (2013) Single-cell Hi-C reveals cell-to-cell variability in chromosome structure. Nature, 502, $59-64$

97. Marti-Renom, M. and Mirny, L. (2011) Bridging the resolution gap in structural modeling of 3D genome organization. PLoS Comput. Biol., 7, e1002125

98. Barbieri, M., Chotalia, M., Fraser, J., Lavitas, L.-M., Dostie, J., Pombo, A. and Nicodemi, M. (2012) Complexity of chromatin folding is captured by the strings and binders switch model. Proc. Natl. Acad. Sci. USA, 109, 16173-16178

99. Dekker, J., Marti-Renom, M. and Mirny, L. A. (2013) Exploring the three-dimensional organization of genomes: interpreting chromatin interaction data. Nat. Rev. Genet., 14, 390-403

100. Barbieri, M., Scialdone, A., Piccolo, A., Chiariello, A. M., di Lanno, C., Prisco, A., Pombo, A. and Nicodemi, M. (2013) Polymer models of chromatin organization. Front. Genet., 4, 113

101. Zhang, Z., Li, G., Toh, K.-C. and Sung, W.-K. (2013) 3D chromosome modeling with semi-definite programming and Hi-C data. J. Comput. Biol., 20, 831-846

102. Varoquaux, N., Ay, F., Noble, W. S. and Vert, J.-P. (2014) A statistical approach for inferring the $3 \mathrm{D}$ structure of the genome. Bioinformatics, 30, i26-i33

103. Rousseau, M., Fraser, J., Ferraiuolo, M. A., Dostie, J. and Blanchette, M. (2011) Three-dimensional modeling of chromatin structure from interaction frequency data using Markov chain Monte Carlo sampling. BMC Bioinformatics, 12, 414

104. Lesne, A., Riposo, J., Roger, P., Cournac, A. and Mozziconacci, J. (2014) 3D genome reconstruction from chromosomal contacts. Nat. Methods, 11, 1141-1143

105. Paulsen, J., Gramstad, O. and Collas, P. (2015) Manifold based optimization for single-cell 3D genome reconstruction. PLoS Comput. Biol., 11, e1004396

106. Hu, M., Deng, K., Qin, Z., Dixon, J., Selvaraj, S., Fang, J., Ren, B. and Liu, J. S. (2013a) Bayesian inference of spatial organizations of chromosomes. PLoS Comput. Biol., 9, e1002893

107. Baù, D., Sanyal, A., Lajoie, B. R., Capriotti, E., Byron, M., Lawrence, J. B., Dekker, J. and Marti-Renom, M. (2011) The three-dimensional folding of the $\alpha$-globin gene domain reveals formation of chromatin globules. Nat. Struct. Mol. Biol., 18, 107-114

108. Wang, S., Xu, J. and Zeng, J. (2015) Inferential modeling of 3D chromatin structure. Nucleic Acids Res., 43, e54

109. DeLano, W. L., Ultsch, M. H., De, A. M., Vos, and Wells, J. A. (2000)
Convergent solutions to binding at a protein-protein. Interface Sci., 287, 1279-1283

110. Nowotny, J., Wells, A., Xu, L., Cao, R., Trieu, T., He, C., and Cheng, J. (2015). GMOL: An Interactive Tool for 3D Genome Structure Visualization. ArXiv150706383

111. Asbury, T. M., Mitman, M., Tang, J. and Zheng, W. J. (2010) Genome3D: A viewer-model framework for integrating and visualizing multi-scale epigenomic information within a three-dimensional genome. BMC Bioinformatics, 11, 444

112. Cremer, T. and Cremer, M. (2010) Chromosome territories. Cold Spring Harb. Perspect. Biol., 2, a003889

113. Li, G.-W. and Xie, X. S. (2011) Central dogma at the single-molecule level in living cells. Nature, 475, 308-315

114. Schmied, J. J., Forthmann, C., Pibiri, E., Lalkens, B., Nickels, P., Liedl, T. and Tinnefeld, P. (2013) DNA origami nanopillars as standards for three-dimensional superresolution microscopy. Nano Lett., 13, 781-785

115. Lu, Y., Zhao, J., Zhang, R., Liu, Y., Liu, D., Goldys, E. M., Yang, X., Xi, P., Sunna, A., Lu, J., et al.(2014) Tunable lifetime multiplexing using luminescent nanocrystals. Nat. Photonics, 8, 32-36

116. Sternberg, S. H. and Doudna, J. A. (2015) Expanding the biologist's toolkit with CRISPR-Cas9. Mol. Cell, 58, 568-574

117. Lomvardas, S., Barnea, G., Pisapia, D. J., Mendelsohn, M., Kirkland, J. and Axel, R. (2006) Interchromosomal interactions and olfactory receptor choice. Cell, 126, 403-413

118. Chen, B., Gilbert, L. A., Cimini, B. A., Schnitzbauer, J., Zhang, W., Li, G.-W., Park, J., Blackburn, E. H., Weissman, J. S., Qi, L. S., et al. (2013) Dynamic imaging of genomic loci in living human cells by an optimized CRISPR/Cas system. Cell, 155, 1479-1491

119. Li, J., Shou, J., Guo, Y., Tang, Y., Wu, Y., Jia, Z., Zhai, Y., Chen, Z., $\mathrm{Xu}, \mathrm{Q}$. and $\mathrm{Wu}, \mathrm{Q}$. (2015) Efficient inversions and duplications of mammalian regulatory DNA elements and gene clusters by CRISPR/ Cas9. J. Mol. Cell Biol., 7, 284-298

120. Guo, Y., Xu, Q., Canzio, D., Shou, J., Li, J., Gorkin, D. U., Jung, I., Wu, H., Zhai, Y., Tang, Y., et al. (2015) CRISPR inversion of CTCF sites alters genome topology and enhancer/promoter function. Cell, $162,900-910$

121. Ma, H., Naseri, A., Reyes-Gutierrez, P., Wolfe, S.A., Zhang, S., and Pederson, T. (2015) Multicolor CRISPR labeling of chromosomal loci in human cells. Proc. Natl. Acad. Sci. USA. 112, 3002-3007

122. Ma, H., Tu, L.-C., Naseri, A., Huisman, M., Zhang, S., Grunwald, D., and Pederson, T. (2016) Multiplexed labeling of genomic loci with dCas9 and engineered sgRNAs using CRISPRainbow. Nat. Biotechnol. Advance online publication, doi:10.1038/nbt.3526 